\title{
Experimental Study of Load Bearing Cold-formed Steel Wall Systems under Fire Conditions
}

Shanmuganathan Gunalan, Prakash Kolarkar and Mahen Mahendran

\begin{abstract}
Light Gauge Steel Framing (LSF) walls made of cold-formed and thin-walled steel lipped channel studs with plasterboard linings on both sides are commonly used in commercial, industrial and residential buildings. However, there is limited data about their structural and thermal performance under fire conditions while past research showed contradicting results about the benefits of using cavity insulation. A new composite wall panel was recently proposed to improve the fire resistance rating of LSF walls, where an insulation layer was used externally between the plasterboards on both sides of the wall frame instead of using it in the cavity. In this research 11 full scale tests were conducted on conventional load bearing steel stud walls with and without cavity insulation, and the new composite panel system to study their thermal and structural performance under standard fire conditions. These tests showed that the use of cavity insulation led to inferior fire performance of walls, and provided supporting research data. They demonstrated that the use of insulation externally in a composite panel enhanced the thermal and structural performance of LSF walls and increased their fire resistance rating. This paper presents the details of the LSF wall tests and the thermal and structural performance data and fire resistance rating of load-bearing wall assemblies lined with varying plasterboard-insulation configurations under two different load ratios. Fire test results including the time-temperature and deflection profiles are presented along with the failure times and modes.
\end{abstract}

Keywords: Fire tests, Light gauge steel frame walls, Steel studs, Plasterboards, Insulation, Standard fire, Elevated temperatures, Load-bearing walls, Fire resistance rating. 


\section{Introduction}

Cold-formed and thin-walled lipped channel sections are commonly used as load bearing wall studs in light gauge steel frame (LSF) walls lined with plasterboards (Figure 1). Under fire conditions, these thin-walled steel sections heat up quickly resulting in a rapid reduction to their strength and stiffness despite the protection offered by fire rated plasterboards. Fire resistance rating of LSF wall systems under standard fire conditions depends on many parameters such as LSF wall configurations (details of plasterboard linings, insulations and their layouts), geometry of LSF wall studs and load ratio. It is important that fire engineers have a good understanding of the fire behaviour and fire resistance rating (FRR) of LSF wall systems and access to simpler design methods capable of predicting their FRR.

The fire behaviour of LSF wall panels has been investigated by many researchers in the past [1-9]. Klippstein [1] found that the interior (cavity) insulation improved the fire resistance of LSF wall panels while Kodur and Sultan [3] and Alfawakhiri [4] revealed that wall assemblies without cavity insulation provided higher fire resistance than cavity insulated assemblies. There is limited data available on the thermal performance of LSF wall systems and past research has often provided contradicting results about the benefits of cavity insulation to the fire rating of LSF walls. Further, past research has mostly been limited to LSF wall systems used in the UK, USA and Canada. The LSF wall systems used in Australia are made of thinner and high strength steels and protected by Australian plasterboards, and their fire behaviour has not been investigated in detail. The Australian building industry is also interested in developing new LSF wall systems with higher fire resistance rating. Therefore a detailed research program was undertaken to investigate the fire performance of Australian LSF wall systems and to develop LSF wall systems with higher FRR. A series of full scale fire tests of LSF walls was conducted first to evaluate the FRR of load bearing LSF wall assemblies. One wall specimen was tested to failure under an axial compression load at room temperature while ten wall specimens subjected to a constant axial compression load were exposed to standard fire conditions on one side to evaluate their fire performance (Table 1). Conventional LSF wall assemblies lined with single or double layers of plasterboard with or without cavity insulation were considered. The insulations used were glass, rockwool and cellulose fibres. A new LSF wall system based on a composite panel was proposed in which the insulation was sandwiched between two plasterboards and this 
composite panel was used on both sides of the wall frame instead of cavity insulation. This externally insulated LSF wall system was also tested using glass, rockwool and cellulose fibres. This paper presents the details of this experimental study and the results.

\section{Test Specimens}

All the steel frames used in the full scale load bearing LSF wall models were built to a height of $2400 \mathrm{~mm}$ and a width of $2400 \mathrm{~mm}$ as shown in Figure 1. The studs and tracks used in the test frames were fabricated from galvanized steel sheets having a nominal base metal thickness of $1.15 \mathrm{~mm}$ and a minimum yield strength of $500 \mathrm{MPa}$. The frames consisted of four vertical studs of $90 \times 40 \times 15 \times 1.15 \mathrm{~mm}$ lipped channel sections (Figure 2 (a)), spaced at $600 \mathrm{~mm}$ centres. They were made by attaching the studs to the top and bottom tracks made of $92 \times 50 \times 1.15$ mm unlipped channel sections (Figure 2 (b)) using $12 \mathrm{~mm}$ long self-drilling wafer head screws.

Test frames were lined on both sides by single or double layers of gypsum plasterboards manufactured by Boral Plasterboard under the product name of Firestop. The plasterboards were $1200 \mathrm{~mm}$ in width by $2400 \mathrm{~mm}$ in length with a thickness of $16 \mathrm{~mm}$ and mass of $13 \mathrm{~kg} / \mathrm{m}^{2}$ [10]. They were installed vertically on both sides of the steel frame to build the single layer wall models. There were two vertical butt joints located over the centre line of stud flanges as shown in Figure 1. The plasterboards were attached to the studs by $25 \mathrm{~mm}$ long drill point screws spaced at $200 \mathrm{~mm}$ centres along the plasterboard edges and $300 \mathrm{~mm}$ centres along the intermediate studs in the field of the plasterboard as shown in Figure 1. A minimum edge distance of $15 \mathrm{~mm}$ was maintained for all the screws from the plasterboard edges. For wall models requiring double layers, the second layer consisted of plasterboard sheets installed horizontally with the joint at mid-height of the wall. The second layer plasterboards were attached by $45 \mathrm{~mm}$ long self-drilling bugle head screws spaced at $300 \mathrm{~mm}$ centres in the field of the plasterboard and penetrating the studs. The vertical and horizontal joints were sealed with $50 \mathrm{~mm}$ wide perforated chamfered edge joint reinforced paper tape and covered with two coats of joint compound. Table 1 shows the details of 11 LSF wall specimens used in this study including the locations of the two vertical plasterboard joints and the two load ratios used. 


\section{Construction of Test Specimens}

Test Specimen 1 was lined on both sides by a single layer of plasterboard covering the frame as shown in Figure 1. It was tested for its ultimate axial compression capacity at ambient temperature. Construction of Test Specimen 2 was similar to that of Test Specimen 1 except for the type of connection at the top end of the studs where a gap of $15 \mathrm{~mm}$ was left between the stud and the upper track as shown in Figure 2 (c). Screws were not used to connect the top end of the studs to the upper track, instead friction fit connections were used. $\mathrm{K}$ type thermocouple wires were installed to measure the temperature variations over the steel stud and plasterboard surfaces. The thermocouple wires were attached to the hot flange, web and cold flange of the studs by passing the hot junctions of the wire through small holes drilled in the steel plate elements.

Test Specimen 3 was constructed with two layers of plasterboard on both sides of the steel frame. The first layer was installed vertically while the second layer was installed horizontally. Friction fit joints (similar to Specimen 2) were used at the top end of the studs. The construction of Test Specimen 4 was very similar to that of Test Specimen 3. However, in this case the top and bottom tracks were connected to the studs with screws. After fixing the two plasterboards on the fire side along with their associated thermocouples the cavity in the wall between the studs was filled with two layers of 50 $\mathrm{mm}$ thick glass fibre mats (with an original nominal density of $13.88 \mathrm{~kg} / \mathrm{m}^{3}$ ) compressed to $90 \mathrm{~mm}$ thickness (cavity depth) giving a density of $15.42 \mathrm{~kg} / \mathrm{m}^{3}$. Figure 3 (a) shows the installation of glass fibre mats. Thereafter the two plasterboard layers on the ambient side were fixed in a manner similar to Test Specimen 3. Construction of Test Specimen 5 was identical to that of Test Specimen 4 except for two $25 \mathrm{~mm}$ thick rockwool layers of density $100 \mathrm{~kg} / \mathrm{m}^{3}$ used as cavity insulation. Figure 3 (b) shows the installation of rockwool mats in the wall cavity and the process of passing the thermocouple wires through small holes drilled into the first plasterboard layer on the ambient side. Test Specimen 6 was built similar to Test Specimens 4 and 5, but with cellulose fibre used as cavity insulation (Figure 3 (c)). After fixing the two plasterboard layers on the fire side along with their associated thermocouple wires the cavity was fine sprayed with plain water to just moisten the cavity facing surface of the plasterboard. This was quickly followed by a wet spray of cellulose fibre until the complete filling of the cavity with an approximate insulation density of $100-110 \mathrm{~kg} / \mathrm{m}^{3}$. The ambient side plasterboards were then fixed to complete the specimen construction. 
Test Specimen 7 required the insulation to be laid outside the cavity (referred to as external insulation) and between the first and second plasterboard layers on both sides of the wall. For this purpose, after fixing the first plasterboard layer, two layers of 13 $\mathrm{mm}$ plasterboard strips of $60 \mathrm{~mm}$ width were fixed to the first plasterboard layer on either side along the periphery of the wall to generate a cavity for external insulation. This was followed by the placing of a single layer of $25 \mathrm{~mm}$ thick glass fibre mat of density $13.88 \mathrm{~kg} / \mathrm{m}^{3}$ (Figure 3 (d)). Finally the second plasterboard layers were fixed horizontally on either side of the wall (sandwiching the insulation between the first and second plasterboard layers). The construction of Test Specimen 8 was identical to Test Specimen 7, except for a single layer of $25 \mathrm{~mm}$ thick rockwool insulation of density 100 $\mathrm{kg} / \mathrm{m}^{3}$ used as external insulation (Figure 3 (e)). In Test specimen 9, in addition to the edge strips, $25 \mathrm{~mm}$ thick cubical spacers cut from plasterboard strips were also positioned in the field of the cavity. This was done to provide firm support to the second plasterboard layer, which was subsequently attached after wet spraying the cavity with cellulose fibre insulation of density $100-110 \mathrm{~kg} / \mathrm{m}^{3}$ (Figure 3 (f)). The second plasterboard layers in Test Specimens 7, 8 and 9 were fixed to the steel frame by $70 \mathrm{~mm}$ long plasterboard screws spaced at $300 \mathrm{~mm}$ centres in the field of the plasterboard. Test Specimens 10 and 11 were constructed similar to Test Specimens 7 and 8, respectively. However, they were tested under a higher load ratio (Table 1).

\section{Fire Test Set-up and Procedure}

\subsection{Gas Furnace}

A propane fired gas furnace was specifically designed and built to conduct the fire tests of LSF wall specimens. Figures 4 (a) and (b) show the furnace with six burners mounted on a carriage with wheels. To start the fire test of LSF walls exposed to heat from one side, the carriage was moved forward to make contact with the frame holding the test wall specimen, thereby completing the combustion chamber (Figure 4 (c)). The inverted parabolic shape of the burner block port works with the vortex and pulls the flame flat onto the furnace wall. This protects the wall from any localised flame impingement and ensures a more uniform temperature distribution over the wall surface, mostly by radiation. The furnace was designed to deliver heat based on the standard fire curve as given by the following equation [11]. 
$\mathrm{T}_{\mathrm{t}}-\mathrm{T}_{\mathrm{o}}=345 \log _{10}(8 \mathrm{t}+1)$

where $t$ is the elapsed time in minutes; $T_{t}$ is the furnace temperature $\left({ }^{\circ} \mathrm{C}\right)$ at time $t$ and $T_{o}$ is the ambient temperature $\left({ }^{\circ} \mathrm{C}\right)$ at the start of the test.

\subsection{Compression Loading Arrangement Used in Ambient and Fire Tests}

The loading frame was specially designed to load the individual studs of LSF wall specimens in compression from the bottom side (Figure 5). Four jacks were mounted on a floor beam at a spacing of $600 \mathrm{~mm}$. The shafts of the jacks were co-axially guided through a hollow sleeve running across a rectangular hollow section (RHS) fixed parallel to the floor beams between the two columns as shown in Figure 5.

Loading plates with collars to house the shafts coming through the RHS were mounted on top of each jack (Figure 5). The test specimen was mounted so that the stud centroids aligned with the centroids of these loading plates. A special arrangement was also made using a sliding plate to facilitate movement of any individual jack with its shaft and sleeve to the extent of $20 \mathrm{~mm}$ on either side to achieve a better accuracy in aligning the centroids of the loading plate and the studs. All the jacks were connected to a single hydraulic pump while a load cell was attached to the pump to obtain the load applied to the studs. The use of a single pump ensured equal loading on all the studs.

\subsection{Instrumentation Details}

The axial shortenings of the studs were measured using four Linear Variable Displacement Transducers (LVDT). Another eight LVDTs were also used to measure the out-of-plane movements of the wall specimen. They were placed at $0.25 \mathrm{H}, 0.50 \mathrm{H}$ and $0.75 \mathrm{H}$ along the height $(\mathrm{H})$ of the two central studs and at mid-height for the exterior studs.

$\mathrm{K}$ type thermocouples were used to measure the temperature development across the wall specimens. The stud temperatures were measured at three levels for interior studs, namely at $0.25 \mathrm{H}, 0.50 \mathrm{H}$ and $0.75 \mathrm{H}$, and at mid-height for exterior studs. At each level three thermocouples were attached per stud to measure the temperatures of the hot flange, web and cold flange. These thermocouples allowed the determination of the average stud temperature and the temperature gradient of the stud across its crosssection and length. To measure the temperatures across the wall depth, three additional 
sets of thermocouples were attached to the plasterboards at the mid-height of the assembly between the studs. Figure 6 shows the locations of thermocouples used in the fire tests. It also shows the stud (Stud 1 to 4 ) and plasterboard (Pb1to Pb4) labeling details and the locations of vertical plasterboard joints against the studs.

The average temperature on the unexposed (ambient) side of the wall was measured using five thermocouples, one at the centre and four at the centres of each quarter section as mentioned in [11]. The temperatures measured by these thermocouples indicated the level of heat penetration across the specimens. An infrared gun was also used to measure the temperatures at other points. The furnace temperature was measured using four K-type furnace thermocouples symmetrically placed inside the furnace chamber at about $100 \mathrm{~mm}$ from the exposed surface of the specimen. Figure 4 (c) shows the test specimen with instrumentation before the fire test.

\subsection{Ambient Temperature Test Procedure}

The test wall specimen was first located within the loading frame. The studs were centred over the individual jacks and the wall specimen was checked for its verticality using spirit levels. The top track was then clamped to the top beam on either side. All four studs were loaded simultaneously in $2 \mathrm{kN}$ increments while recording the load and displacement readings. The specimen was considered failed when the applied load could not be maintained.

\subsection{Fire Test Procedure}

Test wall specimens were installed within the loading frame and set-up as described in the last section for the ambient temperature test. The furnace was then moved towards the wall specimen and the gaps were packed with Isowool. The cement board was used to minimize the heat loss from the upper track of the test specimen to the top beam and also from the bottom track to the loading plates. An axial compression load of $15 \mathrm{kN}$ (for a load ratio of about 0.2 ) or $30 \mathrm{kN}$ (for a load ratio of about 0.4 ) was applied to each stud by the hydraulic jacks (ie. 0.2 or 0.4 times the ultimate capacity of each stud at ambient temperature as obtained from Test 1). The load was held constant at room temperature before the furnace was started and then maintained throughout the fire test. This allowed free vertical expansion of the wall when exposed to elevated temperatures as in the past researches. During the fire test, the furnace temperature was regulated 
such that the average temperature recorded by the control thermocouples inside the furnace followed the standard temperature-time curve (Equation 1) [11]. The vertical and lateral displacements of the wall and the temperature readings of the thermocouples were taken at 1 minute intervals. The test was stopped immediately after one or more of the wall studs failed, and the time to failure was recorded.

\section{Test Observations and Results}

\subsection{Test Specimen 1 under Ambient Temperature Conditions}

The wall specimen showed no visible signs of deformation up to a load of $52 \mathrm{kN}$. Beyond this load the web elements of Studs 1 and 4 showed local buckling deformations, and the wall specimen failed at a load of $79 \mathrm{kN} / \mathrm{stud}$. Lateral movement of the wall specimen was not visible and the failure was due to local buckling of the flange and web elements at the base as shown in Figure 7.

The single layer of plasterboard on each side showed no damage and was successful in effectively restraining the studs from flexural buckling about the minor axis and torsional buckling. The screws connecting the plasterboards to the studs appeared to have pulled through the plasterboard at the base near the locally buckled stud sections.

\subsection{Test Specimens 2 to 11 under Fire Conditions}

All the load bearing wall specimens tested for fire resistance showed similar initial response during the tests. They showed hardly any signs of stress or lateral deformation when subjected to a total axial compression load of $60 \mathrm{kN}$ (15 kN/stud, giving a load ratio of 0.2 ) and $120 \mathrm{kN}$ (30 kN/stud, giving a load ratio of 0.4). Upon starting the furnace, smoke and steam were seen to escape from the periphery of the specimen after three to four minutes. The smoke indicated the burning of the paper on the fire side plasterboard layer and the steam was due to the escape of moisture (both free and chemically bound) from the plasterboards. The presence of steam was noted as it condensed on the inner sides of the loading frame. The specimens also displayed periods of steady burning with little or no smoke or steam after the complete burning of the paper and the complete conversion of water into steam from the plasterboard. The smoke and steam reappeared with subsequent layers of plasterboard heating up. There were periods of thick smoke ensuing continuously from the specimens, which indicated 
the burning of the insulation used in the walls. Amongst the three insulations used, cellulose fibre was seen to produce the maximum smoke and rockwool the minimum.

Lateral deflections were visible in the cavity insulated specimens after about an hour of fire test. In the case of externally insulated specimens, the lateral deflections became noticeable only towards the end of the test. In both cases, the deflection of the wall was initially towards the furnace. Near the end of the test, a reversal of lateral deflection was observed in all the specimens (except Specimen 11) forcing the wall to deform in the outward direction. Maintaining the applied load was difficult at this stage. The failure was sudden in all the specimens with rapid load reduction, buckling of studs, and cracking of plasterboards on the ambient side.

The failure criteria of LSF wall panel can be in terms of structural adequacy, integrity or insulation. Integrity is defined as the ability to resist flames or smoke passing through the section [11]. The assembly is considered to have failed by the insulation criterion when the average temperature rise on the unexposed surface exceeds $140^{\circ} \mathrm{C}$, or the maximum temperature rise at any point exceeds $180^{\circ} \mathrm{C}[11,12]$. The structural adequacy criteria shall be deemed to have occurred when either a collapse occurs or when the deflection exceeds its limit. In this study the ambient surface of wall specimens recorded values well below the insulation failure temperature throughout the test and the wall specimen failure was due to the structural failure of the studs in all the tests.

Figures 8 to 17 show the average time-temperature profiles of the plasterboard and steel surfaces and the axial deformation and lateral deflection versus time curves for Test specimens 2 to 11, respectively. The notations used in these figures are based on Figure 6 and Table 2. Other results obtained from these tests such as the measurements taken at different wall heights are given in [13,14].

\subsubsection{Fire Side Plasterboard Layer (Pb1) in Test Specimens 2-11}

In all the tests, the temperature of the ambient side of the fire side plasterboard layer developed in three phases. In the first phase the temperature rose quickly to about $100^{\circ} \mathrm{C}$ while in the second phase, it was maintained at about $100^{\circ} \mathrm{C}$ due to the energy consumed in converting the free and chemically bound water present in the plasterboard into steam. In the third phase, this temperature increased again. In Test Specimen 2 a 
sharp rise in temperature beyond $500^{\circ} \mathrm{C}$ (in Pb1-Cav) indicates the breaching of the exposed plasterboard. This is confirmed with the Pb2-Cav profile almost merging with the Pb1-Cav profile towards the end of the test. In Test Specimen 3 (double plasterboards) the temperature curve of the $\mathrm{Pb1}-\mathrm{Pb} 2$ surface appeared to be parallel to the fire curve maintaining a difference of approximately $150^{\circ} \mathrm{C}$ to $200^{\circ} \mathrm{C}$ until the end. This indicates that the integrity of $\mathrm{Pb} 1$ was maintained until failure where the unexposed side temperature of $\mathrm{Pb} 1$ was just above $900^{\circ} \mathrm{C}$. Similar behavior was also observed in Test Specimen 4 where this temperature was just below $900^{\circ} \mathrm{C}$ at failure. In Test Specimen 5 individual temperature profile of $\mathrm{Pb} 1-\mathrm{Pb} 2$ in the left section of the wall (i.e. between Studs 1 and 2) merged with the fire side curve at about 88 minutes signifying gradual collapse of parts of exposed plasterboard when the temperature of unexposed side of $\mathrm{Pb} 1$ was nearly $900^{\circ} \mathrm{C}$. In Test Specimen 6 the temperature profiles of the individual thermocouples placed in the three regions of the wall (left, middle and right) showed that the temperature profile of $\mathrm{Pb} 1-\mathrm{Pb} 2-\mathrm{L}$ meets the fire side curve at about 79 minutes indicating a partial collapse of $\mathrm{Pb} 1$ in this region where the temperature of unexposed side of $\mathrm{Pb} 1$ was nearly $900^{\circ} \mathrm{C}$. In Test Specimen 7 visual observations and careful analyses of individual thermocouple measurements revealed that the left side plasterboard pieces (Pb1) had fallen off at 86 minutes where the unexposed side temperature of $\mathrm{Pb} 1$ was again above $900^{\circ} \mathrm{C}$. In Test Specimen $8 \mathrm{a}$ temperature difference of $100-150^{\circ} \mathrm{C}$ was noticed across the plasterboard thickness until the end of the test. This suggested that the integrity of the fire side plasterboard was maintained until the failure of the specimen where the temperature of the unexposed side of Pb1 was well above $900^{\circ} \mathrm{C}$. In Test Specimen 9 the thermocouple positioned at the centre between Studs 1 and 2 showed a continuous increase in its temperature finally merging with the fire curve at about 88 minutes indicating a breach of the external plasterboard in this area. This time the temperature of the unexposed side of $\mathrm{Pb} 1$ was just below $900^{\circ} \mathrm{C}$. In Test specimen 10 the middle plasterboard pieces had fallen off at 85 minutes when the unexposed side temperature of $\mathrm{Pb} 1$ was above $900^{\circ} \mathrm{C}$. Similarly the left side plasterboard (Pb1) pieces had fallen off at 86 minutes in Specimen 11 when the unexposed side temperature of $\mathrm{Pb} 1$ was nearly $900^{\circ} \mathrm{C}$. These observations are helpful to update the findings of [15] which reported that plasterboard fall-off occurs when the unexposed face of the plasterboard reaches about $600^{\circ} \mathrm{C}$. Our results show that when two layers are used on either side of the LSF wall, the 
plasterboard fall-off occurs when the temperature of the unexposed face of the plasterboard reaches about $900^{\circ} \mathrm{C}$.

\subsubsection{Fire Side Base Plasterboard Layer $(\mathrm{Pb} 2)$ in Test Specimens 3-9}

In Test Specimen 3 during the last phase the temperature gradient of $\mathrm{Pb} 2-\mathrm{Cav}$ curve was fairly constant and maintained a temperature difference of approximately $400^{\circ} \mathrm{C}$ with the $\mathrm{Pb} 1-\mathrm{Pb} 2$ interface. The maintenance of this temperature difference until the end of the test indicates the continued integrity of plasterboard 2 until the failure of Test Specimen 3. Similar behavior was observed for Test Specimens 4 and 6 with a temperature difference of $200^{\circ} \mathrm{C}$ and $250^{\circ} \mathrm{C}$, respectively, across the plasterboard thickness until the end of the test. In Test Specimen 5, the base layer plasterboard in the left region must have severely calcinated compared to other regions as it collapsed at about 106 minutes following the structural failure of the wall. In Test Specimen 7 a temperature difference of approximately $450^{\circ} \mathrm{C}$ was present across the thickness of Plasterboard 2 by the end of the test, indicating the sustained integrity of the exposed base plasterboard layer until failure. It appears to have provided sufficient lateral restraint to the studs as the studs did not suffer from torsional buckling or flexural buckling about the minor axis. In Specimen 8 after 80 minutes, linear temperature growth rate was observed in $\mathrm{Pb} 2-\mathrm{Cav}$ crossing $300^{\circ} \mathrm{C}$ by 105 minutes (compared to $720^{\circ} \mathrm{C}$ by the same time in Specimen 5 using the same insulation in the cavity). The surface recorded a temperature of $450^{\circ} \mathrm{C}$ by 135 minutes near the end of the test which also happened to be the temperature difference across the plasterboard thickness demonstrating its integrity until failure. In Test Specimen 9, beyond 70 minutes a linear temperature growth rate was observed for $\mathrm{Pb} 2-\mathrm{Cav}$ and the temperature reached $400^{\circ} \mathrm{C}$ by 108 minutes and $500^{\circ} \mathrm{C}$ by 120 minutes (compared with 68 and 72 minutes in Specimen 6). After 125 minutes the temperature difference across the plasterboard thickness was approximately $475^{\circ} \mathrm{C}$, which reduced sharply soon after indicating its partial collapse.

\subsubsection{Cavity Insulation in Test Specimens 4-6}

In Test Specimen 4 the temperature difference across the thickness of glass fibre insulation in the cavity was about $500^{\circ} \mathrm{C}$ when the test was terminated. This indicated that the glass fibre insulation maintained its integrity and was not burnt until the failure of the specimen. In Test Specimen 5 the rockwool insulation seemed to have maintained 
its integrity throughout the test as no sudden increment in temperature was noted in the Pb3-Cav surface temperature. The temperature across the insulation was approximately $550^{\circ} \mathrm{C}$ at the end of the test. The temperature difference across the thickness of the cellulose fibre insulation was close to $200^{\circ} \mathrm{C}$ at the end of the test in Test Specimen 6. A sharp rise in the temperature of the Pb3-Cav surface after 110 minutes indicates the quick deterioration of the cellulose fibre in the wall cavity.

\subsubsection{External Insulations in Test Specimens 7-9}

In Test Specimen 7, beyond 35 minutes the temperature gradient of Pb1-Ins curve started to reduce with the temperature crossing $700^{\circ} \mathrm{C}$ by 45 minutes and $752^{\circ} \mathrm{C}$ by 53 minutes. This is because the glass fibre insulation has started to melt by this time and the heat was used for this chemical process rather than for the temperature rise. After 54 minutes Ins- $\mathrm{Pb} 2$ curve approached the fire side temperature curve indicating the complete burning of the glass fibre insulation. In Test Specimen 8 after 110 minutes a constant temperature difference of about $100^{\circ} \mathrm{C}$ was maintained between Ins-Pb2 and Pb1-Ins curves. This indicated the intactness of the rockwool insulation used as external insulation between Plasterboards 1 and 2 until failure. In Test specimen 9, the merging of Ins-Pb2 curve with Pb1-Ins at about 106 minutes indicates the total disintegration of cellulose fibre insulation.

Figure 18 shows the variation of applied load with time and confirms the failure of Test Specimen 11 after 134 minutes. Similar plots were obtained for all other tests to confirm the failure time.

\subsection{Test Specimen 2 (Single Plasterboard without Insulation - LR of 0.2)}

Most of the fire side plasterboard (Pb1) remained attached to the steel frame until failure. The lateral deflection was towards the furnace and the maximum deflection at mid-height of the wall prior to failure was $28 \mathrm{~mm}$. The total thermal expansion of the studs during the fire test was in the range of 5 to $7.5 \mathrm{~mm}$. The presence of plasterboard joints along the stud height affected the behavior and failure of Studs 2 and 4. Shrinkage of the exposed plasterboard caused it to detach from the fasteners, opening the joints and exposing the studs as shown in Figure 19 (a). Studs 2 and 4 with vertical plasterboard joints on the fire side underwent larger thermal bowing deformations due to higher thermal gradients across the cross-section. This caused them to separate from 
the ambient side plasterboard, pulling the screws inwards as shown in Figure 19 (a). The reduced lateral support on either side of the studs caused these studs to undergo flexural torsional buckling about the minor axis. Stud 4 also failed by local buckling near the support due to reduced mechanical properties at elevated temperatures. The failure occurred after 53 minutes of standard fire exposure, that is, the fire resistance rating (FRR) of this wall system is 53 minutes.

\subsection{Test Specimen 3 (Two Plasterboards without Insulation - LR of 0.2)}

The fire side plasterboards $(\mathrm{Pb} 1$ and $\mathrm{Pb} 2)$ remained attached to the steel frame until failure. The lateral deflection was initially towards the furnace and then reversed its direction after 67 minutes. The maximum mid-height deflection at that time was $16 \mathrm{~mm}$. On the removal of exposed plasterboards ( $\mathrm{Pb} 1$ and $\mathrm{Pb} 2)$ it was noticed that the studs had laterally displaced at the top end. The friction fit joints provided at the top end of studs had failed to prevent the slipping of the studs in the lateral direction at elevated temperatures. This bending of the studs about the minor axis near the top of the wall caused the screws to pull out from the plasterboard. Figure 19 (b) shows the test specimen after removing the exposed side plasterboards. The central studs also displayed distortional buckling in the top one third portion of their lengths. The failure of test specimen occurred after 111 minutes of standard fire exposure.

\subsection{Test Specimen 4 (Two Plasterboards with GF Cavity Insulation - LR of 0.2 )}

The fire side plasterboards ( $\mathrm{Pb} 1$ and $\mathrm{Pb} 2)$ remained attached to the steel frame until failure. The portions of plasterboard in the lower right hand area of the wall fell off after the structural failure of the wall. The lateral deflection was initially towards the furnace and then reversed in direction at the end of 85 minutes. The maximum mid-height deflection at that time was $32 \mathrm{~mm}$. The fire side plasterboards appeared to have provided sufficient restraint to the studs and hence the studs did not undergo any buckling failures associated with twisting as shown in Figure 20 (a). Studs 1, 2 and 3 from the right side of the wall failed by local buckling (compressive failure) of the hot flange near the mid-height resulting in the reversal of lateral displacement and the outward movement of the wall. Test specimen 4 failed after 101 minutes of fire exposure (FRR of 101 minutes). 


\subsection{Test Specimen 5 (Two Plasterboards with RF Cavity Insulation - LR of 0.2)}

The fire side plasterboards ( $\mathrm{Pb} 1$ and $\mathrm{Pb} 2)$ remained attached to the steel frame until failure. The lateral deflection was initially towards the furnace and then reversed in direction after 92 minutes. The maximum mid-height deflection at that time was $35 \mathrm{~mm}$. The specimen failed after 107 minutes deflecting laterally in the outward direction due to the local compressive failure of the hot flanges and a flexural bending action about the major axis (Figure 20 (b)).

\subsection{Test Specimen 6 (Two Plasterboards with CF Cavity Insulation - LR of 0.2)}

$\mathrm{Pb} 1$ breached partially at about 78 minutes between Studs 1 and 2, whereas Pb2 remained attached to the steel frame until failure. The lateral deflection of the specimen was initially towards the furnace and reversed in direction after 96 minutes. The midheight deflection at that time was $35 \mathrm{~mm}$. Figure 20 (c) shows the test specimen after the fire test, which failed after 110 minutes of fire exposure. Cellulose fibre used in the cavity had completely burnt out leaving behind a black residue. The paper on the cavity facing surface of Plasterboard 3 had also burnt out completely. The central studs were seen to be severely damaged. Stud 1 showed some local buckling of the hot flange at $370 \mathrm{~mm}$ from the bottom while Stud 4 was undamaged. In Studs 2 and 3 the local buckling of the hot flange involved screw pull-out through the plasterboard, thus doubling the buckling length of the flange leading to rapid outward movement of the studs causing the punching of the plasterboard on the ambient side. Stud 3 also displayed local crushing near the top support.

\subsection{Test Specimen 7 (Two Plasterboards with GF External Insulation - LR of 0.2)}

From the beginning of the test, the wall specimen was bending towards the furnace. However, near the failure, the lateral deflection started to reverse its direction and finally the studs bent away from the furnace, resulting in the breaking of plasterboards. The test was stopped after 118 minutes. Parts of the exposed plasterboards (Pb1 and $\mathrm{Pb} 2$ ) were seen to have fallen off near the centre of the specimen exposing the Pb3-Cav surface. However, the temperature measurements indicate that $\mathrm{Pb} 2$ must have fallen off due to increasing lateral deflection at the failure point. The glass fibre insulation used between Plasterboards 1 and 2 had completely disappeared leaving only some molten glass traces. The flexural buckling about the minor axis and the torsional buckling of studs were fully prevented by the lateral support offered by the plasterboards throughout 
the test. The exposed plasterboards were stripped off to expose the frame and this view shows the presence of local buckling waves along the studs, confirming the occurrence of local buckling of studs before the ultimate failure (Figure 21 (a)).

\subsection{Test Specimen 8 (Two Plasterboards with RF External Insulation - LR of 0.2)}

The fire side Plasterboards 1 and 2 remained attached to the steel frame until failure. The lateral deflection was initially towards the furnace and reversed in direction after 123 minutes (Figure 21 (b)). The maximum mid-height deflection at that time was 23 $\mathrm{mm}$. The test specimen failed after 136 minutes of fire exposure. The front view of the specimen after removing the external plasterboards and insulation shows the studs without any torsional or flexural buckling about the minor axis as the studs were laterally supported adequately. Figure 21 (b) shows the local buckling waves in Studs 1 to 3. Severe local buckling near the mid-height led to an outward movement of the studs and thus breaking of the ambient side plasterboards. The failure time could have been higher if not for the additional loading of studs caused by the closure of the expansion gap provided in the loading mechanism (Figure 21 (b)).

\subsection{Test Specimen 9 (Two Plasterboards with CF External Insulation - LR of 0.2)}

The fire side Plasterboard 1 collapsed partially near the central portion of the wall after 73 minutes whereas Plasterboard 2 remained attached to the steel frame until failure. The lateral deflection was initially towards the furnace and reversed in direction after 110 minutes. The maximum mid-height deflection at that time was $22 \mathrm{~mm}$. The test specimen failed after 124 minutes of fire exposure. Plasterboards 1 and 2 had fully collapsed and the cellulose fibre between them was totally burnt out (Figure 21 (c)). This figure also shows the outward movement of the studs caused by the local compressive failure of the stud hot flanges. Studs 1 to 3 were severely damaged by the local buckling of hot flange and web elements.

\subsection{Test Specimen 10 (Two Plasterboards with GF External Insulation - LR of}

\section{4)}

The only difference between Test Specimens 7 and 10 was in the applied load. Therefore as expected the measured time-temperature profiles were very similar. The behaviour of Test Specimen 10 was also very similar to that of Test Specimen 7. The test failure time was 108 minutes. From the beginning, the wall was observed to be 
bending towards the furnace. However, near the failure, the lateral deflection reversed its direction and finally the studs bent away from the furnace, resulting in the breaking of plasterboards. Figure 22 (a) shows the test specimen after the fire test. Studs 1 and 4 did not fail nor experienced any local buckling. Stud 2 showed local buckling waves in the web. Stud 3 was severely bent about the major axis and showed local buckling of the entire cross-section near mid-height. Local buckling waves were observed in the web even away from mid-height. This observation confirms that local buckling of studs occurred first, which led to their ultimate failure.

\subsection{Test Specimen 11 (Two Plasterboards with RF External Insulation - LR of}

\section{4)}

The wall specimen bent towards the furnace until failure, which occurred after 134 minutes (Figure 22 (b)). The face layer of exposed plasterboards (Pb1) appeared to have fallen off near the centre, thus exposing the rock fibre insulation. The rock fibre insulation used between Plasterboards 1 and 2 was still there without any integral failure. Stud 1 did not fail in this test while Stud 4 experienced local web buckling along the length. Stud 2 bent severely about the major axis and showed local buckling of the entire cross-section near the mid-height. Local failure was also observed at the support. Stud 3 showed local buckling waves even away from mid-height and the entire section has failed due to local failure at the support.

\section{Discussion of Results}

\subsection{Comparison between the conventional LSF walls and the proposed externally insulated LSF walls}

In all the fire tests, the central studs that had the vertical plasterboard joints (Table 1) were subjected to more heat flow due to the opening of joints in Plasterboard 2. Their temperatures were higher than those of other studs at any given time and thus the wall failure was also influenced and initiated by the failure of these studs. Hence these critical studs were considered in the following discussions.

The average hot flange temperature profiles of the critical stud for Test Specimens 3 to 9 are shown in Figure 23 (a). A distinct separation in the time-temperature profiles of the studs in these wall specimens shows that the studs of the externally insulated wall specimens are well protected and thus take longer time to reach the temperatures 
attained by the studs in the cavity insulated specimens. The hot flange temperatures of the externally insulated specimens are substantially lower than the hot flange temperatures of non-insulated and cavity insulated test specimens. In the case of cavity insulated specimens, the temperature plateau of the hot flanges lasted only up to 40 minutes in comparison to 65 minutes in the externally insulated specimens. The hot flange temperature profiles of the cavity insulated specimens show that the thermal response of the studs is identical for rockwool and cellulose fibre insulations whereas for glass fibre insulation the stud temperatures are marginally higher. This signifies a low influence on the stud temperatures by the material of insulation used in the cavity. This is probably because, in the cavity insulated specimens, the insulation is on the ambient side of the hot flange and thus incapable of offering any protection to it. In the case of externally insulated specimens, the temperature profiles of the studs are well separated implying the effect of the material of insulation on the stud temperatures. Figure 23 (a) shows that rockwool insulation offers the maximum protection to the studs (lowest hot flange temperatures).

Because of the very low conductivity of the cavity insulating material as compared to steel, most of the heat gets directed and channeled along and across the steel studs which act as the heat sink thus raising their temperatures much faster than in the case of non-cavity insulated specimens. This makes the very presence of cavity insulation a threat to the survival of steel studs during fire conditions. Externally insulated specimens on the other hand can offer a much higher level of protection to the studs as they are installed on the fire side of the studs thus minimizing the transfer of heat by radiation (by virtue of their physical presence) and conduction (on account of their low conductivity). Hence the quality of insulation used externally would directly influence the level of fire protection offered to the studs. Rockwool insulation when used externally was seen to give the maximum protection.

The temperature difference between the hot and cold flanges of the central studs with the passage of time during the fire test is shown in Figure 23 (b). The graphs were drawn using the average temperature values of the hot and cold flanges of the critical studs. The hot flange temperatures of cavity insulated specimens were seen to rise very rapidly with large temperature differences across the stud cross-sections due to the presence of insulation between the flanges in the wall cavity. The hot flange 
temperatures of externally insulated wall specimens on the other hand were seen to rise gradually with a small temperature difference across the stud cross-sections due to the faster transfer of heat by radiation across the empty cavity. The lateral deformations were proportional to the temperature difference across the stud cross-sections. The higher temperature differences across the stud cross-sections in the cavity insulated specimens led to higher lateral deformations than in the externally insulated specimens (Figures 10 to 15). Hence the presence of a highly non-uniform temperature distribution across the studs with higher hot flange temperatures in the cavity insulated specimens has led to reduced structural performance of studs under fire conditions.

Table 3 gives the failure times and the hot flange temperatures at failure for the load bearing wall specimens tested under standard fire conditions. It must be noted that these failure times are in fact the fire resistance rating of these wall systems. Only the failure times of Test Specimens 3 to 11 can be compared as they have two plasterboards on either side of the frame. The failure times of the cavity insulated specimens were less than that of Test Specimen 3 without cavity insulation, however, the failure times of externally insulated specimens were the highest, confirming the superior performance of the newly developed composite wall panels. Table 3 also shows that the temperature difference across the stud (and hence thermal bowing effects) was much higher in the cavity insulated wall panels compared to non-insulated and externally insulated wall panels.

\subsection{Failure Direction of LSF Walls}

The LSF wall studs are subject to non-uniform temperature distributions when the wall is subjected to fire on one side. Figure 24 shows the stud centroid location at mid-height at such non-uniform elevated temperatures. It will be at the geometric centre of the stud at the beginning of the tests. Once the fire test is commenced, thermal bowing will be induced by the non-uniform temperature distribution across the stud. The centroid location at mid-height will therefore move towards the fire side $\left(e_{\Delta T}\right)$. In addition to this the effective centroid of the stud will shift towards the ambient side due to the loss of stiffness (reduced elasticity modulus) of the hotter side of steel stud. This effect is known as neutral axis shift $\left(e_{\Delta E}\right)$. The net eccentricity can thus be expressed by $e=e_{\Delta T}$ $e_{\Delta E}$. The value of e and thus the position of $\mathrm{Z}$ in Figure 24 will vary depending on the values of $e_{\Delta T}$ and $e_{\Delta E}$, which depend on the temperature distributions of the stud cross- 
section. During the initial stages of the test, thermal bowing will be induced by the temperature variation across the wall, even before the stud temperatures have increased significantly. Hence $e_{\Delta T}$ will be more than $e_{\Delta E}$, which will result in a positive value for $e$. Therefore the wall will move towards the furnace initially. However, near failure at higher non-uniform temperature distributions $e_{\Delta E}$ will increase rapidly. With reducing $e$ values, the LSF wall will start to move away from the furnace. The above explains the reason for the observed failure directions of LSF walls.

The failure direction also depends on the comparative strengths of cold and hot flanges near the failure time. This can be explained by investigating the behaviour of Test Specimens 10 and 11 subjected to the same load ratio of 0.4 . Test Specimen 11 survived more time due to the superior performance of rockwool compared to glass fibre (134 versus 108 minutes). However, at failure the cold flange temperature is higher in Test Specimen $11\left(432^{\circ} \mathrm{C}\right)$ than in Test Specimen $10\left(386^{\circ} \mathrm{C}\right)$. This is due to the heat transfer from the hot side to the cold side during this additional time. Therefore Test 11 failure was towards the furnace by compressive failure of the cold flange near mid-height. This is because the heat penetrated well into the ambient side of the steel stud to reduce the strength of cold flange below the applied stress. However, in Test 10 there was not enough time for the heat to be transferred from hot flange to cold flange and hence the acceleration of fire side temperature reduced the strength of hot flange below the applied stress. This resulted in overall movements away from the furnace by the local buckling failure of the hot flange.

\subsection{Plasterboard Performance}

Figures 8 (a) to 17 (a) present the time-temperature profiles for plasterboard surfaces for all the tests. They clearly demonstrate how they are able to protect the thin-walled steel studs from extremely high temperatures from a standard fire test. The expected second plateau in the time-temperature graph of the plasterboards due to the conversion of the remaining portion (approximately 25\%) of the chemically bound water present in the plasterboard, into steam was never observed. This was probably because the conversion of the small quantity of bound water into steam was very quick and the steam was able to escape across the plasterboard thickness very fast without much of re-condensation or migration towards the ambient side due to the already present numerous shrinkage cracks over the entire body of the plasterboard. 
In the design of LSF wall studs, the assumption of in-plane lateral restraint provided by the base fire side plasterboard ( $\mathrm{Pb} 2)$ plays a significant role. It should be able to support $3 \%$ of the compressive load in the critical flange [16]. However, the load resistance at each point of restraint should not be less than 1\%. Klippstein [1] assumed that the failure by weak axis flexural buckling or torsional buckling will be prevented by the plasterboard on both faces of the wall. However, Gerlich et al. [2] stated that when steel temperatures reach critical levels $\left(>300-400^{\circ} \mathrm{C}\right)$ the fire side plasterboard will reduce its ability to prevent buckling of the studs due to degradation. They used a thinner unexposed lining $(9.5 \mathrm{~mm})$ for a test to achieve an insulation failure. However, it was found that the unexposed lining failed to provide lateral support after it had degraded. Hence they recommended a $3 \mathrm{~mm}$ thickness of undamaged gypsum to be retained to provide resistance to lateral buckling. Alfawakhiri [4] assumed that the flexuraltorsional and weak axis buckling failure modes are prevented by bridging and blocking. Hence the question of lateral restraint by plasterboards was not raised in his study. Kaitila [5] checked the occurrence of flexural-torsional buckling mode when the temperature during the fire test increased beyond the level of calcination of the plasterboards (about $550^{\circ} \mathrm{C}$ ). Hence the lateral restraint was no longer considered to be valid on the fire side. Feng et al. [7] and Zhao et al. [9] assumed that fire side plasterboards could provide lateral restraint to the studs.

In the current study the fire side plasterboard of Test Specimen 2 calcinated and lost its ability to provide lateral restraint to the studs. However in other wall specimens (3 to 11), where two plasterboard layers were used on either side of the wall, the integrity of the fire side base layer ( $\mathrm{Pb} 2$ ) was maintained until failure. This is verified in the experimental study where minor axis lateral or torsional buckling failure modes were not observed in the studs due to plasterboard fall-off. Further the minimum temperature difference between the faces of $\mathrm{Pb} 2$ was about $200^{\circ} \mathrm{C}$ for cavity insulated panels while it was more than $400^{\circ} \mathrm{C}$ for non-insulated and externally insulated wall panels until failure. This may also suggest that $\mathrm{Pb} 2$ did not fully calcinate and lose its ability to provide lateral restraint to studs. Hence in the numerical modelling of LSF walls, both (hot and cold) flanges of the studs can be considered to be laterally restrained by plasterboards until failure. 


\subsection{Effect of Load Ratios}

Test Specimens 7 and 11 were identical except for the applied load level. Therefore the time-temperature profiles across the wall panels (Figure 25 (a)) were almost identical. The temperature profiles across the critical stud in Figure 25 (b) also show that they are also identical with a negligibly small time lag. At failure the temperatures of web and flanges were higher for Specimen 7 compared to Specimen 11 due to lower applied loads. The curves of lateral deflections versus time for the critical stud from Tests 7 and 11 are shown in Figure 25 (c). This figure shows that the curves are similar for Tests 7 and 11. After about 100 minutes, both test specimens reversed their lateral deflection and moved away from the furnace. Therefore it is considered that these measured temperature profiles and axial and lateral axial deflections can be used in numerical analyses of such wall specimens with varying load ratios.

Further discussion of the structural and thermal performance of tested LSF wall panels is given in $[13,14]$ based on detailed evaluation of measured time-temperature and deflection profiles.

\section{Conclusions}

This paper has presented the details of eleven full scale LSF wall panels tested under standard fire conditions to study the thermal and structural performance of load bearing wall assemblies lined with single or double layers of plasterboards with and without cavity insulation and the new composite panel in which an insulation was used externally between the plasterboards. Detailed fire test results including the timetemperature and deflection profiles are presented along with the stud failure modes and wall failure times. Test results showed that the proposed cold-formed steel stud wall systems with external insulation provided higher fire resistance rating than the conventional cavity insulated wall systems. The effects of load ratios are also presented in this paper. The time-temperature distributions of the studs were alike for thermally similar wall panels although they were tested with different load ratios. This paper has presented valuable structural and thermal performance data for LSF walls with various plasterboard-insulation configurations that can be used in future numerical studies of LSF wall systems. 


\section{Acknowledgements}

The authors would like to thank Australian Research Council for their financial support and the Queensland University of Technology for providing the necessary facilities and support to conduct this research project.

\section{References}

[1] Klippstein, K.H. (1980), Strength of Cold-Formed Studs Exposed to Fire, American Iron and Steel Institute. Washington DC, USA.

[2] Gerlich, J.T., Collier, P.C.R. and Buchanan, A.H. (1996), Design of Steel-framed Walls for Fire Resistance, Fire and Materials, Vol.20, No.2, pp.79-96.

[3] Kodur, V.R. and Sultan, M.A. (2001), Factors governing fire resistance of loadbearing steel stud walls, Proceeding of the Fifth AOSFST International Conference, Newcastle, Australia, pp.1-2.

[4] Alfawakhiri, F. (2001), Behaviour of Cold-formed-Steel-framed Walls and Floors in Standard Fire Resistance Tests, PhD Thesis. Carleton University, Ottawa, Ontario, Canada.

[5] Kaitila, O. (2002), Finite Element Modelling of Cold-formed Steel Members at High Temperatures, Licentiate Thesis, Helsinki University of Technology, Espoo, Finland.

[6] Feng, M., Wang, Y.C. and Davies, J. M. (2003a), Thermal Performance of Coldformed Thin-walled Steel Panel Systems in Fire, Fire Safety Journal, Vol.38, pp.365-394.

[7] Feng, M., Wang, Y.C. and Davies, J.M. (2003b), Axial Strength of Cold-formed Thin-walled Steel Channels under Non-uniform Temperatures in Fire, Fire Safety Journal, Vol.38, pp.679-707. 
[8] Feng, M. and Wang, Y.C. (2005), An Experimental Study of Loaded Full-Scale Cold-Formed Thin-Walled Steel Structural Panels Under Fire Conditions, Fire Safety Journal, Vol. 40, pp. 43-63.

[9] Zhao, B., Kruppa, J., Renaud, C., O’Connor, M., Mecozzi, E., Apiazu,. W., Demarco, T., Karlstrom, P., Jumppanen, U., Kaitila, O., Oksanen, T. and Salmi, P. (2005), Calculation Rules of Lightweight Steel Sections in Fire Situations, Technical Steel Research, European Union, France.

[10] Standards Australia (SA) (1998), AS/NZS 2588 Gypsum Plasterboard, Sydney, Australia.

[11] Standards Australia (2005), AS 1530.4 Methods for Fire Tests on Building Materials, Components and Structures, Part 4: Fire-resistance Tests of Elements of Building Construction, Sydney, Australia.

[12] ISO 834-1, (1999), Fire Resistance Tests - Elements of Building Construction Part 1: General Requirements, International Organization for Standardization, Geneva, Switzerland.

[13] Kolarkar, P.N. (2010), Fire Performance of Plasterboard Lined Steel Stud Walls, PhD Thesis, Queensland University of Technology, Brisbane, Australia.

[14] Gunalan, S. (2011), Structural Behaviour and Design of Cold-formed Steel Wall Systems under Fire Conditions, PhD Thesis, Queensland University of Technology, Brisbane, Australia.

[15] Sultan, M.A. (1996), A Model for Predicting Heat through Non-insulated Unloaded Steel-Stud Gypsum Board Wall Assemblies Exposed to Fire, Fire Technology, Vol. 32, No. 3, pp. 239-259.

[16] British Standards Institution (BSI) (1998), Structural Use of Steelwork in Building, BS 5950, Part 5 Code of Practice for Design of Cold-formed Thin Gauge Sections, London, UK. 
Table 1: Details of LSF Wall Specimens

\begin{tabular}{|c|c|c|c|c|c|}
\hline $\begin{array}{c}\text { Test } \\
\text { Specimen }\end{array}$ & Configuration & Condition & Insulation & Load Ratio & $\begin{array}{c}\text { Vertical } \\
\text { Plasterboard } \\
\text { Joints } \\
\end{array}$ \\
\hline 1 & एБ口 & Ambient & None & 0.2 & Studs 2 and 4 \\
\hline 2 & एदE & Fire & None & 0.2 & Studs 2 and 4 \\
\hline 3 & \begin{tabular}{ll|lll}
$\mathrm{L}$ & $\mathrm{L}$ & $\mathrm{L}$ & $\mathrm{I}$ \\
\end{tabular} & Fire & None & 0.2 & Studs 2 and 4 \\
\hline 4 & निम & Fire & $\begin{array}{c}\text { Glass Fibre } \\
\text { (Cavity Insulation) }\end{array}$ & 0.2 & Studs 2 and 4 \\
\hline 5 & मिए: & Fire & $\begin{array}{c}\text { Rock Fibre } \\
\text { (Cavity Insulation) }\end{array}$ & 0.2 & Studs 2 and 4 \\
\hline 6 & A & Fire & $\begin{array}{l}\text { Cellulose Fibre } \\
\text { (Cavity Insulation) }\end{array}$ & 0.2 & Studs 1 and 3 \\
\hline 7 & 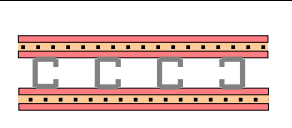 & Fire & $\begin{array}{c}\text { Glass Fibre } \\
\text { (External Insulation) }\end{array}$ & 0.2 & Studs 1 and 3 \\
\hline 8 & 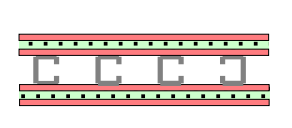 & Fire & $\begin{array}{c}\text { Rock Fibre } \\
\text { (External Insulation) }\end{array}$ & 0.2 & Studs 2 and 4 \\
\hline 9 & 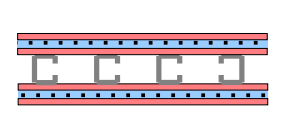 & Fire & $\begin{array}{c}\text { Cellulose Fibre } \\
\text { (External Insulation) }\end{array}$ & 0.2 & Studs 2 and 4 \\
\hline 10 & $\begin{array}{r}\square \quad \square \quad \\
\square \quad \square\end{array}$ & Fire & $\begin{array}{c}\text { Glass Fibre } \\
\text { (External Insulation) }\end{array}$ & 0.4 & Studs 1 and 3 \\
\hline 11 & 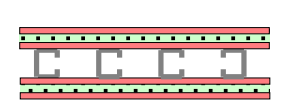 & Fire & $\begin{array}{c}\text { Rock Fibre } \\
\text { (External Insulation) }\end{array}$ & 0.4 & Studs 2 and 4 \\
\hline
\end{tabular}


Table 2: Notations used in Figures

\begin{tabular}{|l|l|c|}
\hline \multicolumn{1}{|c|}{ Notation } & \multicolumn{1}{|c|}{ Description } & $\begin{array}{c}\text { Test } \\
\text { Specimens }\end{array}$ \\
\hline FS & Surface of fire side face layer & $2-11$ \\
\hline Pb1-Cav & Cavity surface of fire side plasterboard layer & 2 \\
\hline Pb2-Cav & Cavity surface of ambient side plasterboard layer & 2 \\
\hline Pb1-Pb2 & Surface between fire side face and base plasterboard layers & $3-6$ \\
\hline Pb3-Pb4 & Surface between ambient side face and base plasterboard layers & $3-6$ \\
\hline Pb2-Cav & Cavity surface of fire side base plasterboard layer & $3-11$ \\
\hline Pb3-Cav & Cavity surface of ambient side base plasterboard layer & $3-11$ \\
\hline Pb1-Ins & Surface between face plasterboard layer and insulation layer & $7-11$ \\
\hline Ins-Pb2 & Surface between insulation and fire side base plasterboard layer & $7-11$ \\
\hline Pb3-Ins & $\begin{array}{l}\text { Surface between ambient side base plasterboard layer and } \\
\text { insulation layer }\end{array}$ & $7-11$ \\
\hline Ins-Pb4 & $\begin{array}{l}\text { Surface between the insulation layer and ambient side face } \\
\text { plasterboard layer }\end{array}$ & $7-11$ \\
\hline Amb & Surface of ambient side & $2-11$ \\
\hline HF, W \& CF & Hot Flange, Web and Cold Flange of Stud & $2-11$ \\
\hline
\end{tabular}


Table 3: Failure Times and Temperatures of LSF Wall Specimens

\begin{tabular}{|c|c|c|c|c|}
\hline $\begin{array}{c}\text { Test } \\
\text { Specimen }\end{array}$ & Configuration & $\begin{array}{c}\text { Failure } \\
\text { Time (min.) }\end{array}$ & $\begin{array}{c}\text { Hot Flange } \\
\text { Temperature } \\
\text { at Failure }\left({ }^{\circ} \mathrm{C}\right)\end{array}$ & $\begin{array}{l}\text { Max. Temp. } \\
\text { Difference } \\
\text { across the } \\
\text { Studs }\left({ }^{\circ} \mathrm{C}\right)\end{array}$ \\
\hline 1 & ए & - & - & - \\
\hline 2 & 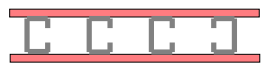 & 53 & 595 & 128 \\
\hline 3 & 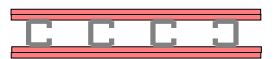 & 111 & 555 & 109 \\
\hline 4 & - a a & 101 & 645 & 342 \\
\hline 5 & 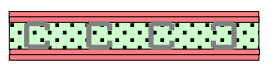 & 107 & 648 & 379 \\
\hline 6 & मrana & 110 & 652 & 326 \\
\hline 7 & |l: & 118 & 656 & 164 \\
\hline 8 & 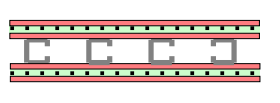 & $136^{*}$ & 500 & 99 \\
\hline 9 & एIC & 124 & 558 & 118 \\
\hline 10 & $\begin{array}{l}\ldots \ldots \ldots \ldots \\
\overline{1} \ldots \ldots \ldots \\
\end{array}$ & 108 & 481 & 139 \\
\hline 11 & 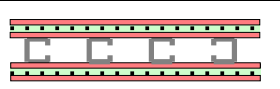 & 134 & 548 & 135 \\
\hline
\end{tabular}

${ }^{*}$ Earlier failure due to lack of space for thermal expansion 


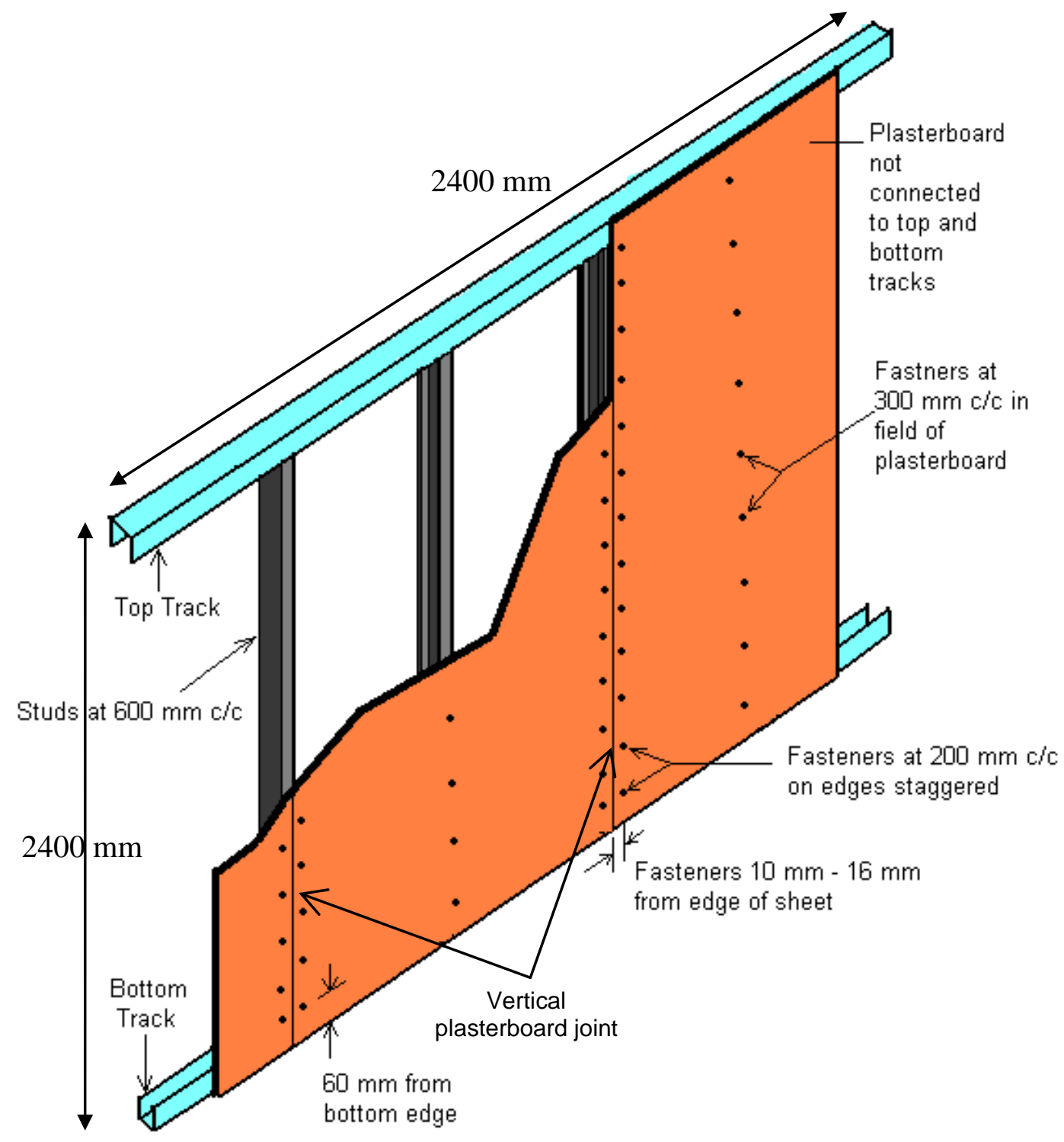

Figure 1: LSF Wall Frames Lined with Plasterboards 


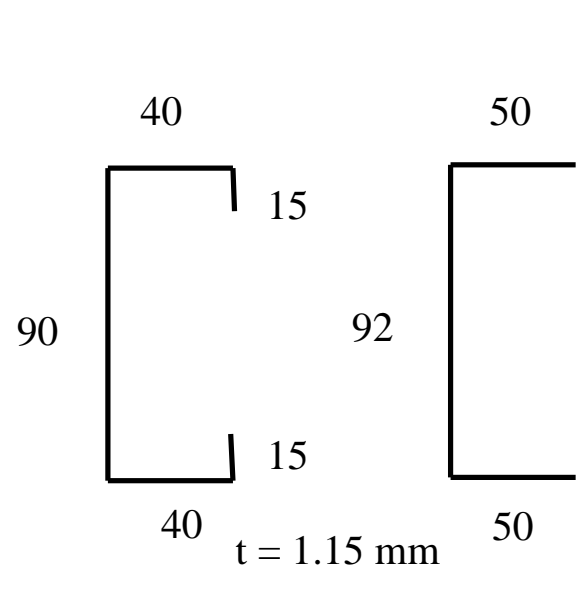

(a) Stud

(b) Track

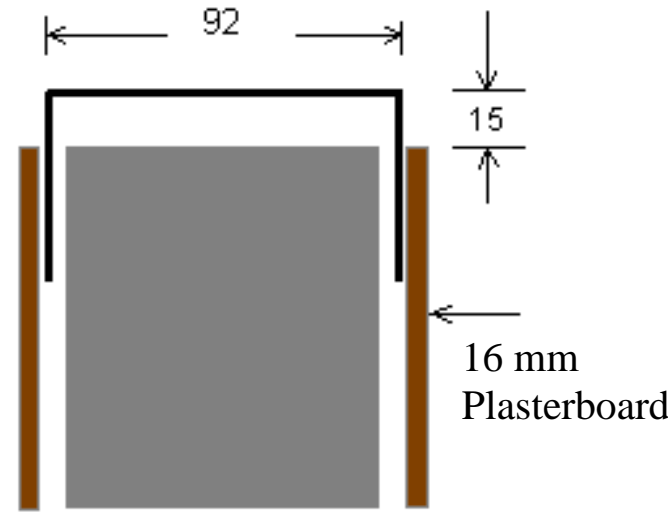

$\leftarrow 90 \longrightarrow$

(c) Connection for Test Specimens 2 and 3

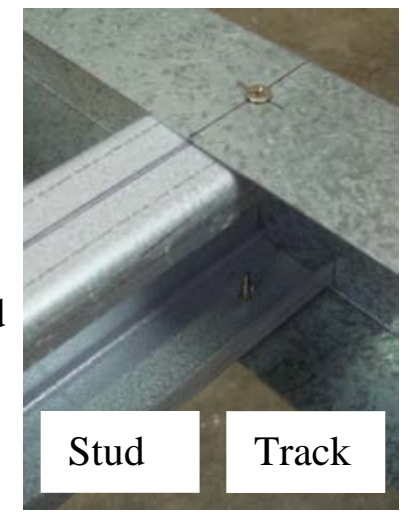

(d) Connection for Test Specimens 1 \& 4-11

Figure 2: Details of Stud and Track and their Connections 


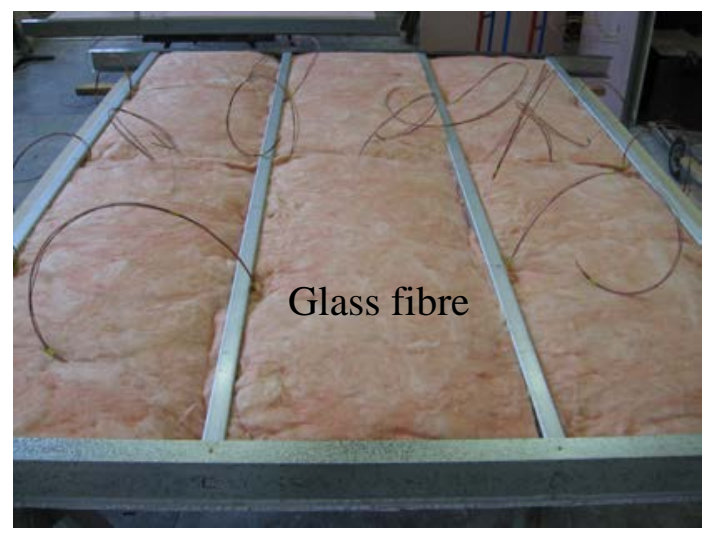

(a) Test Specimen 4

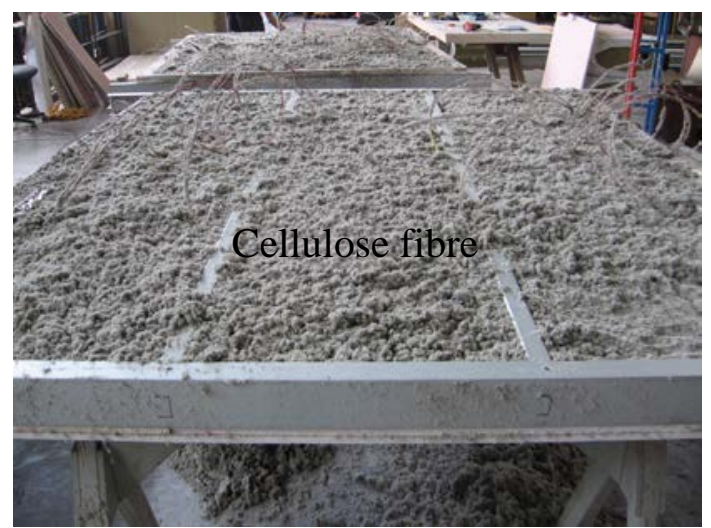

(c) Test Specimen 6

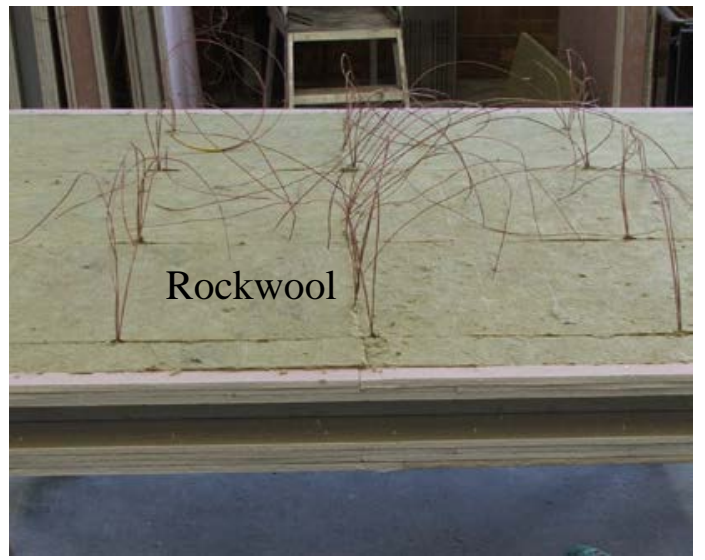

(e) Test Specimens 8 and 11

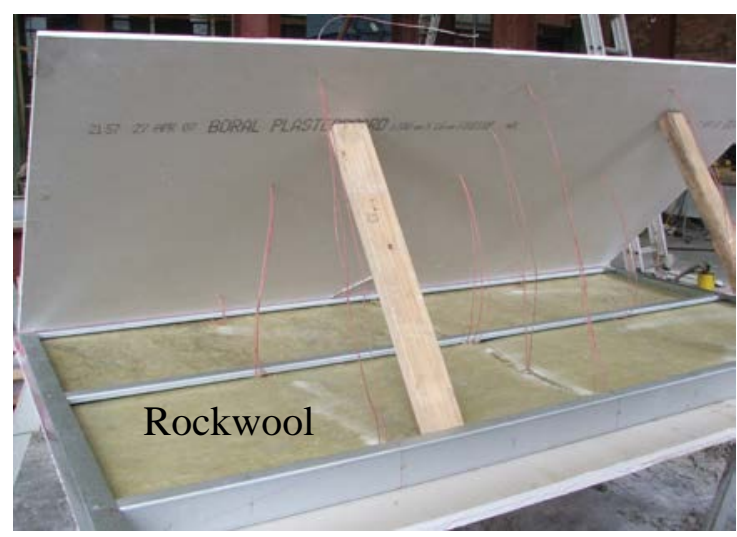

(b) Test Specimen 5

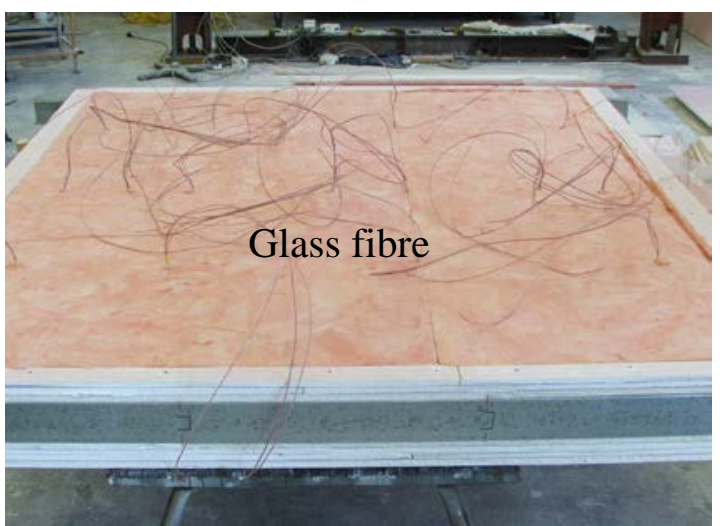

(d) Test Specimens 7 and 10

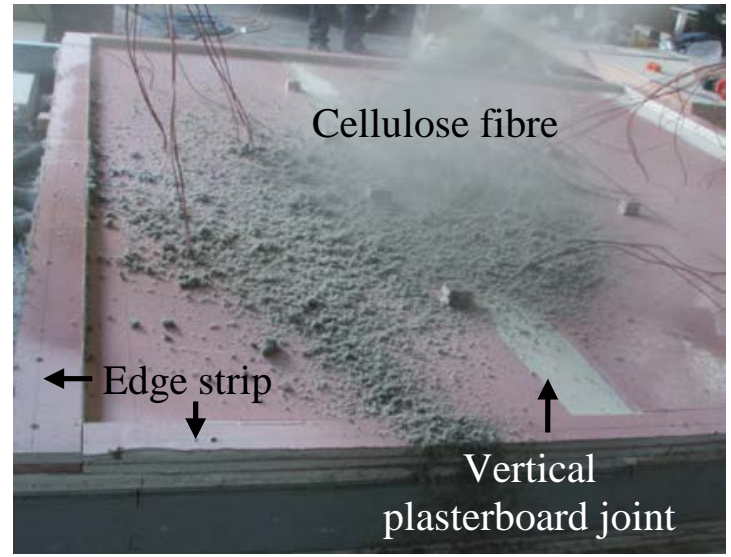

(f) Test Specimen 9

Figure 3: Construction of Test Specimens 


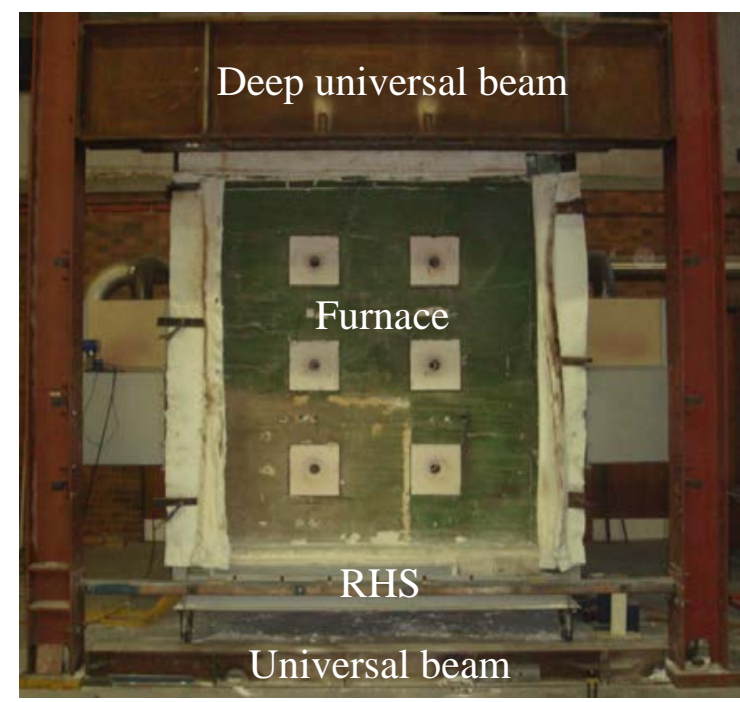

(a) Loading Frame and Furnace

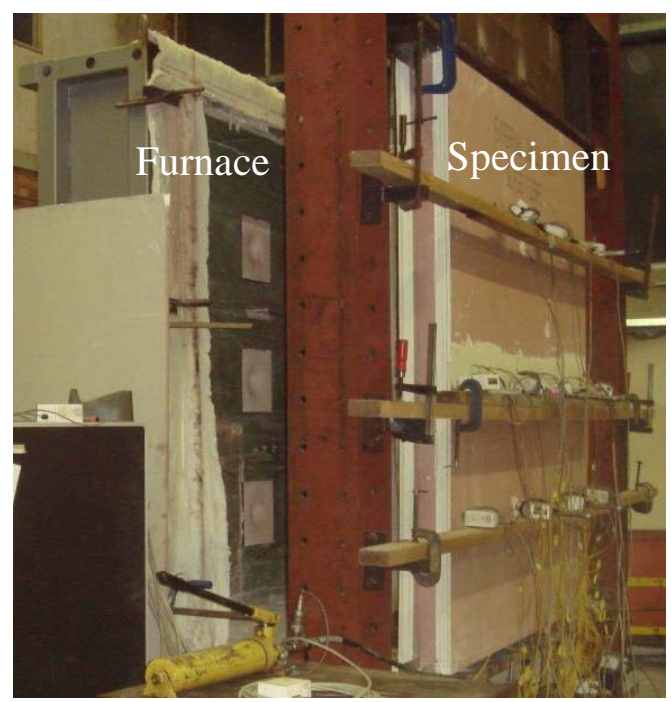

(b) Side View

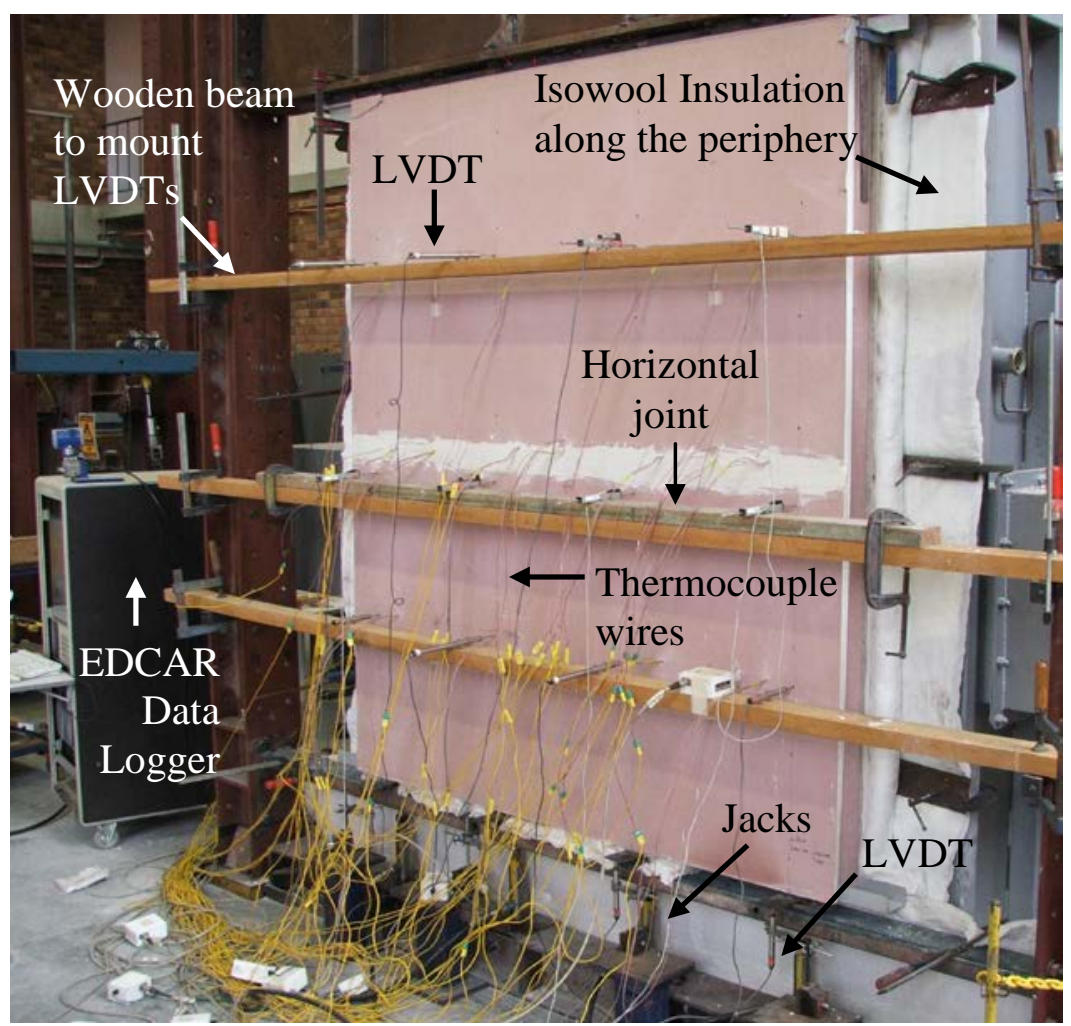

(c) Test Specimen Before Testing

Figure 4: Fire Test Set-up 

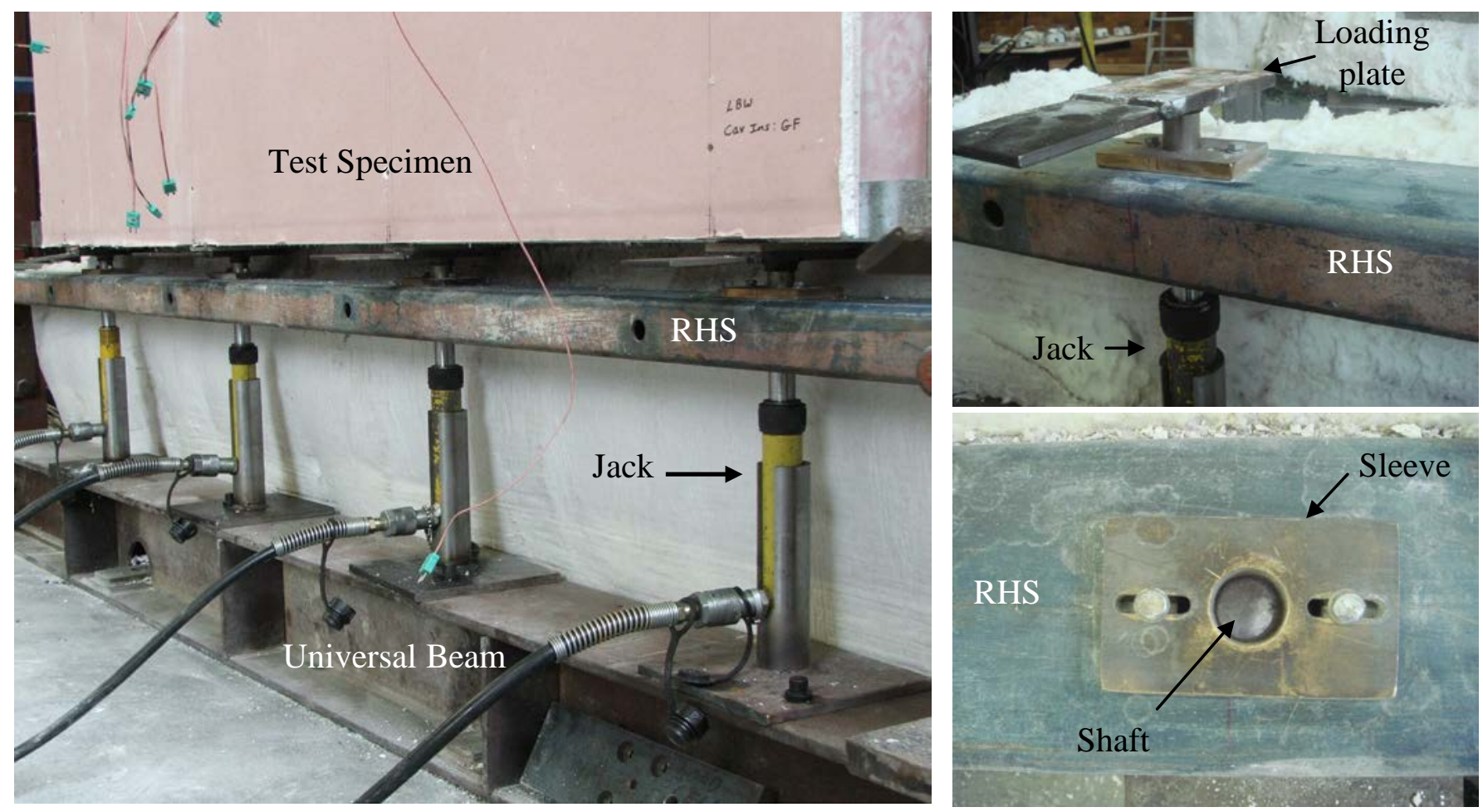

Figure 5: Loading Arrangement 
Fire exposed side

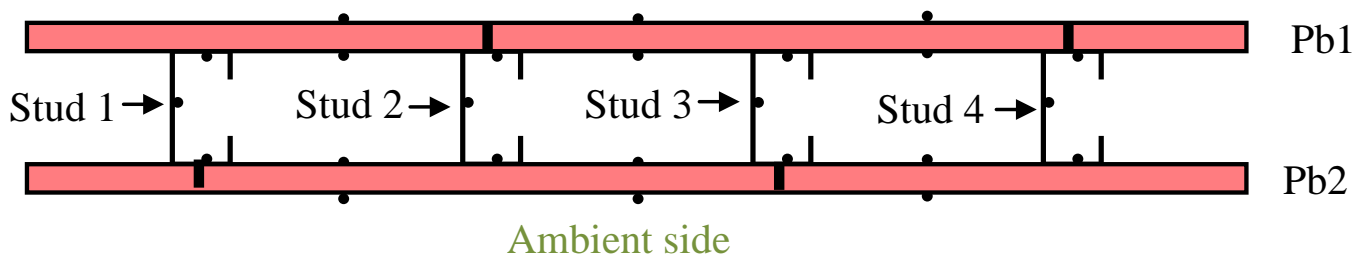

(a) 1x1 Wall Specimen

Fire exposed side

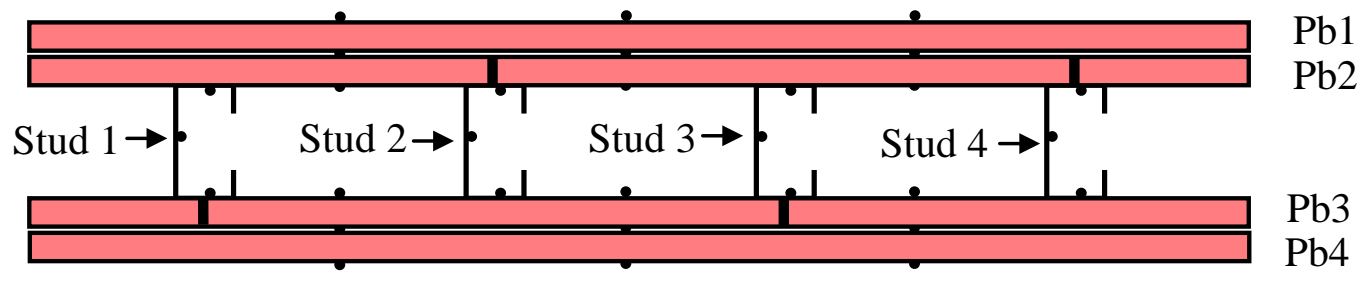

Ambient side

(b) 2x2 Wall Specimens with and without Cavity Insulation

Fire exposed side

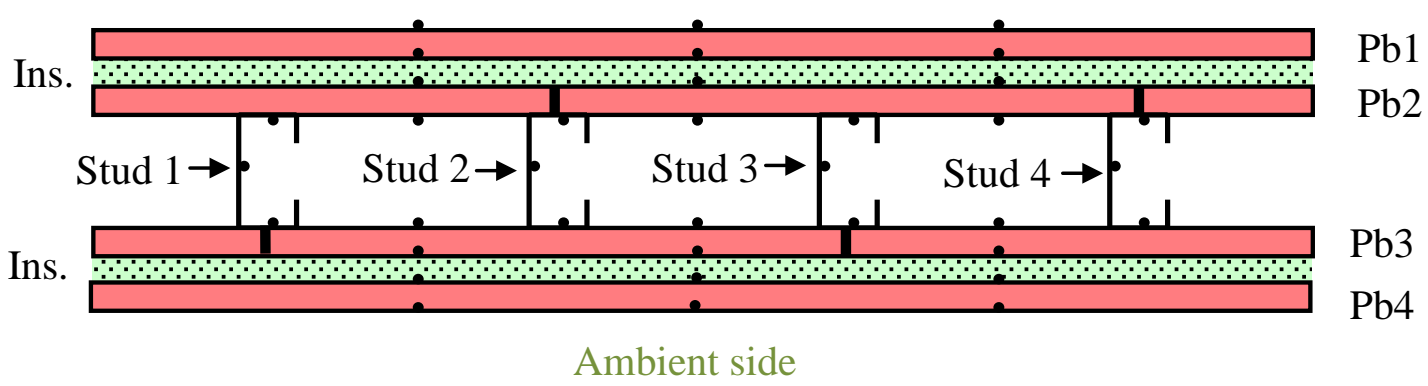

(c) 2x2 Wall Specimens with External Insulation
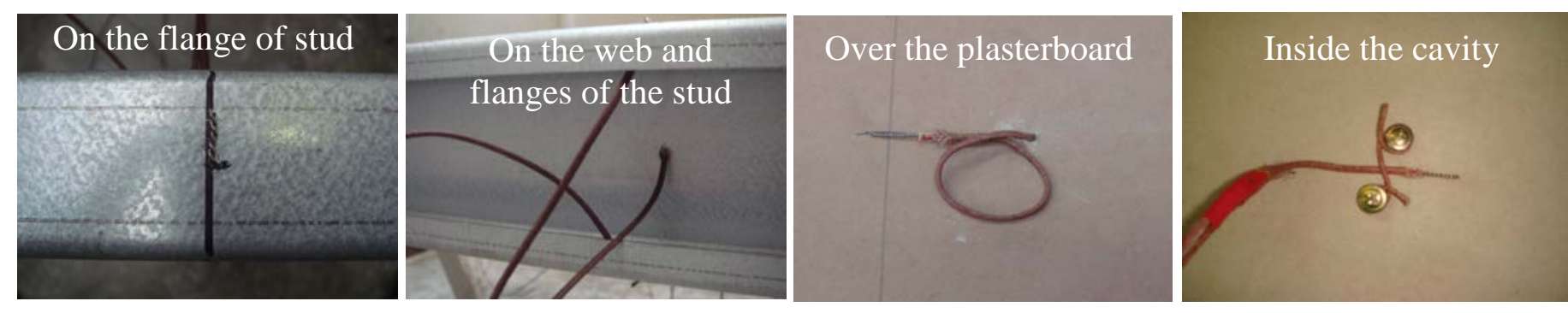

(d) Thermocouple fixings

Figure 6: Thermocouple Locations for Wall Specimens 


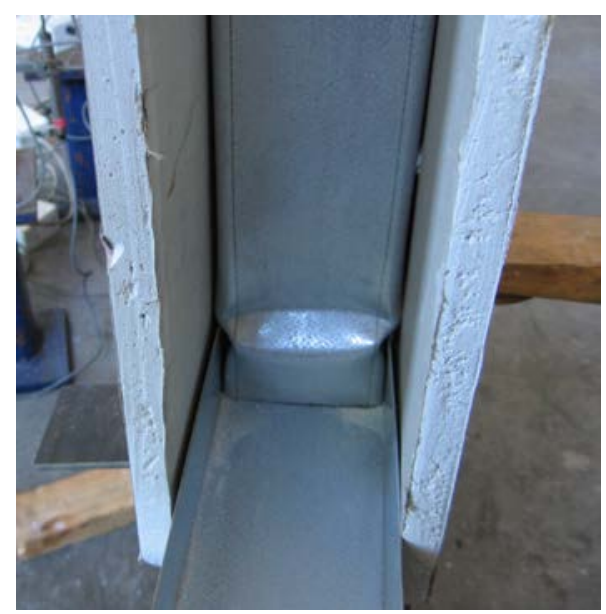

Figure 7: Local Buckling Failure of Test Specimen 1 


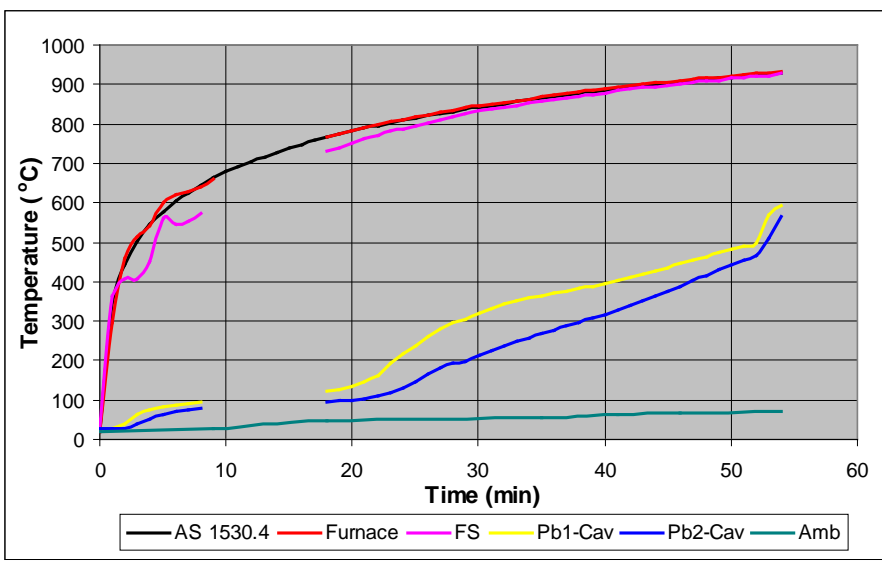

(a) Average Time-Temperature Profiles of Plasterboard Surfaces

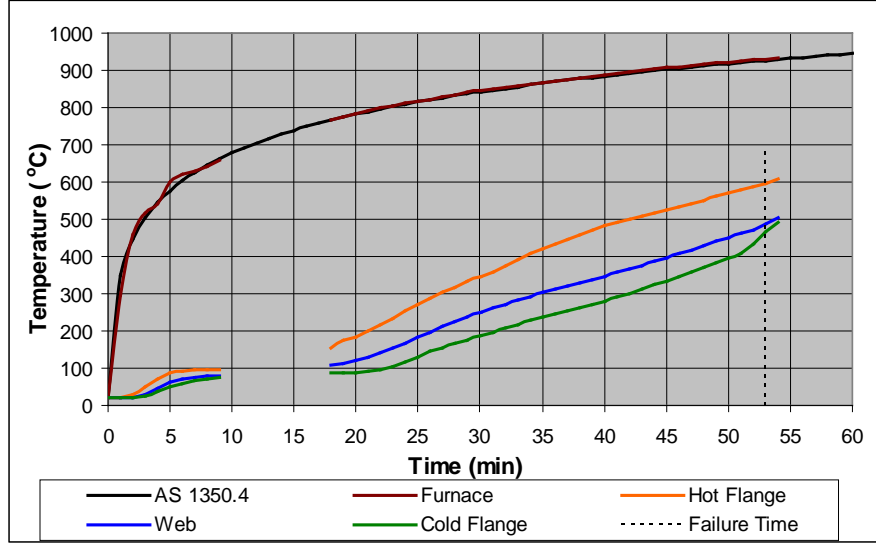

(b) Time-Temperature Profiles across Stud 2

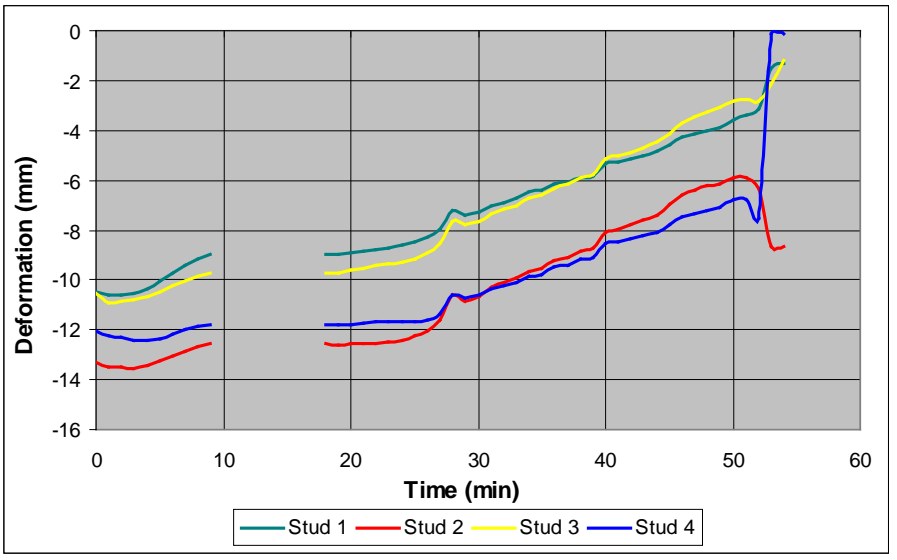

(c) Axial Deformation -Time Profiles of Studs

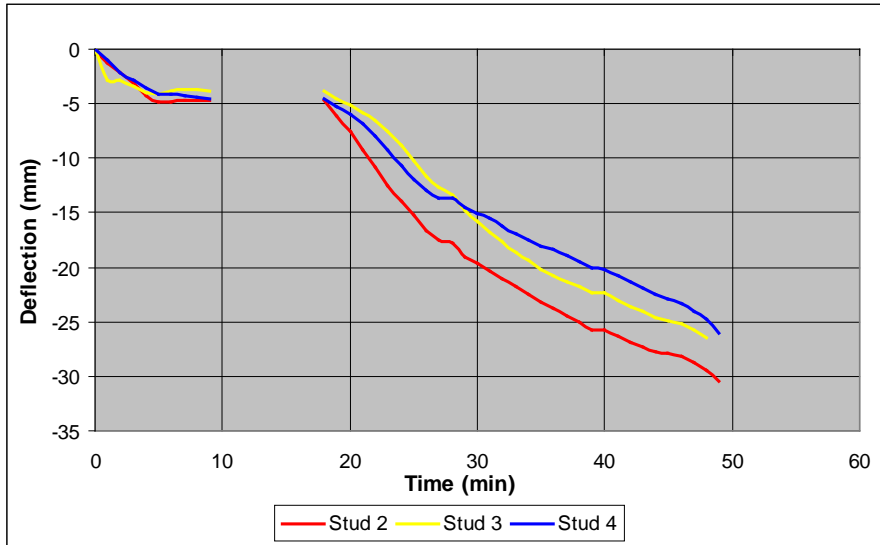

(d) Lateral Deflection -Time Profiles of Studs at Mid-height

Figure 8: Results for Test Specimen 2 


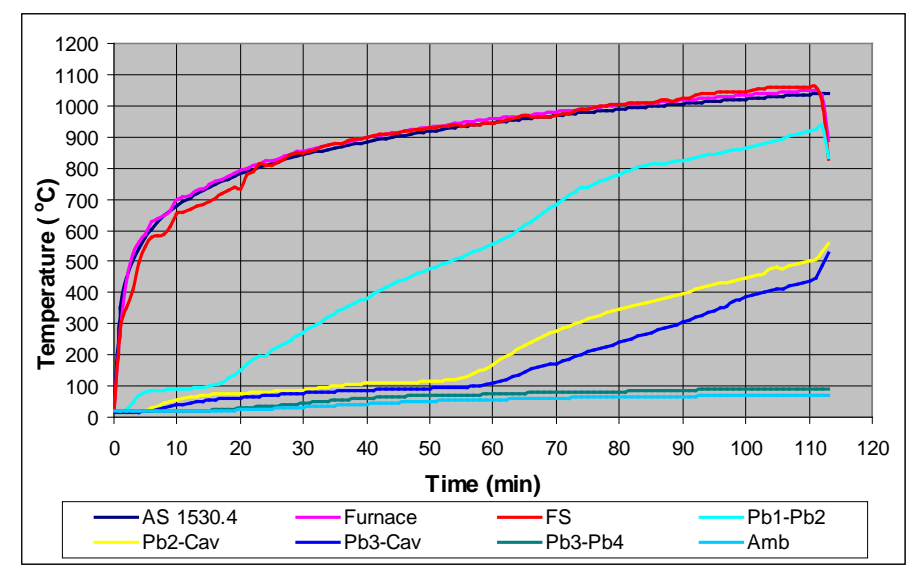

(a) Average Time-Temperature Profiles of Plasterboard Surfaces

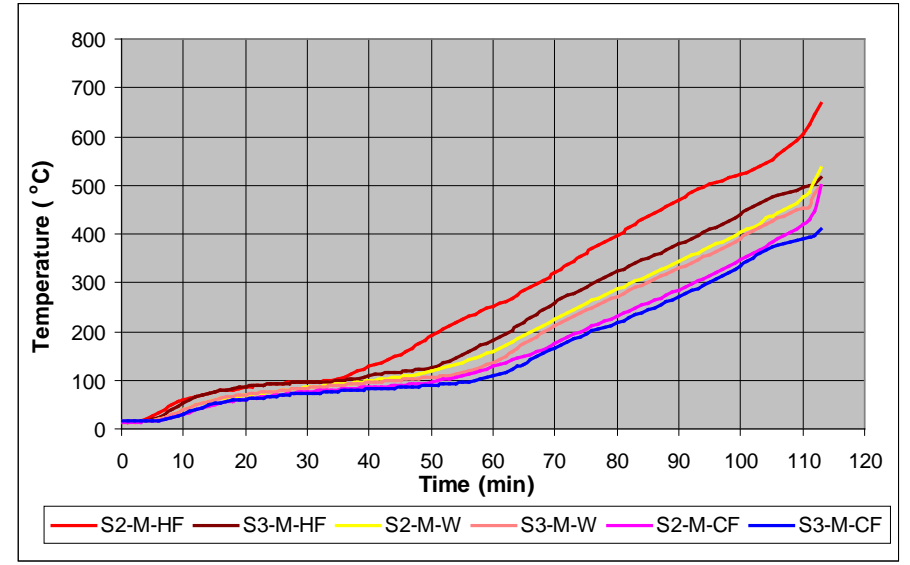

(b) Time-Temperature Profiles across Central Studs at Mid-height

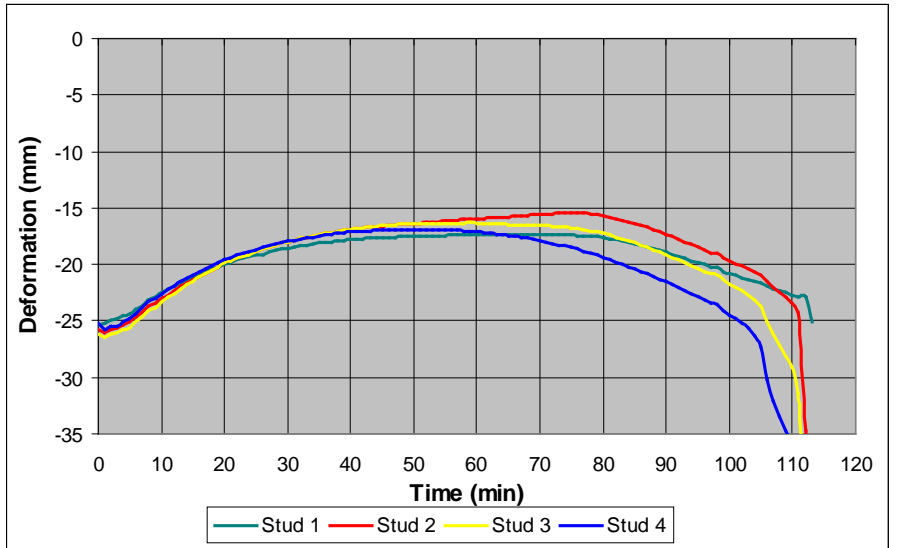

(c) Axial Deformation -Time Profiles of Studs

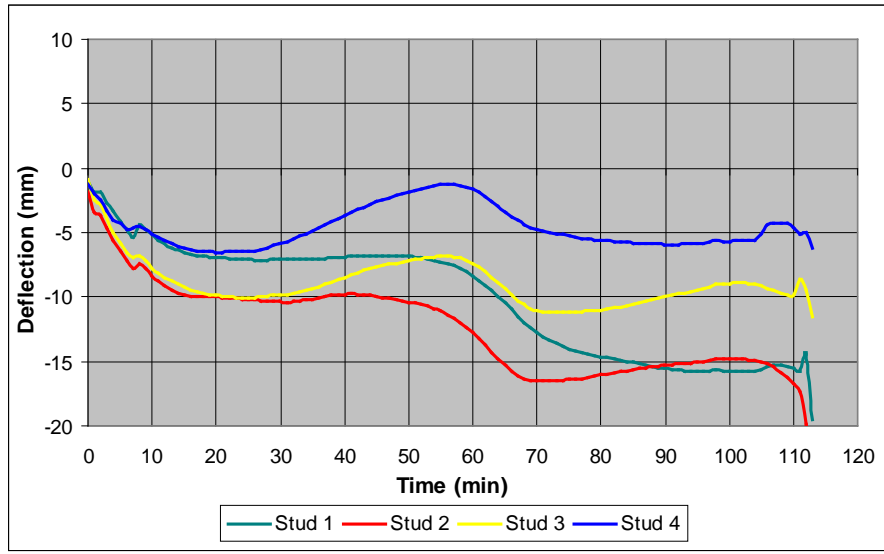

(d) Lateral Deflection -Time Profiles of Studs at Mid-height

Figure 9: Results for Test Specimen 3 


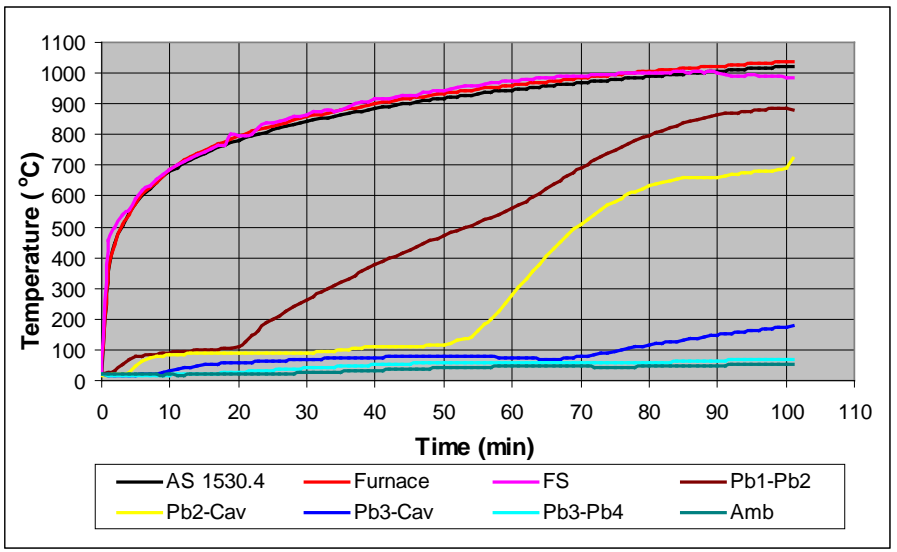

(a) Average Time-Temperature Profiles of Plasterboard Surfaces

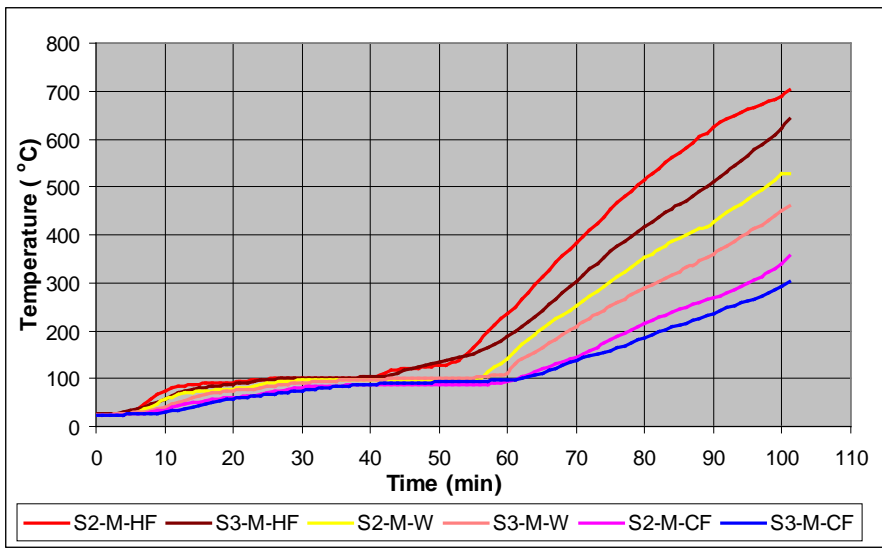

(b) Time-Temperature Profiles across Central Studs at Mid-height

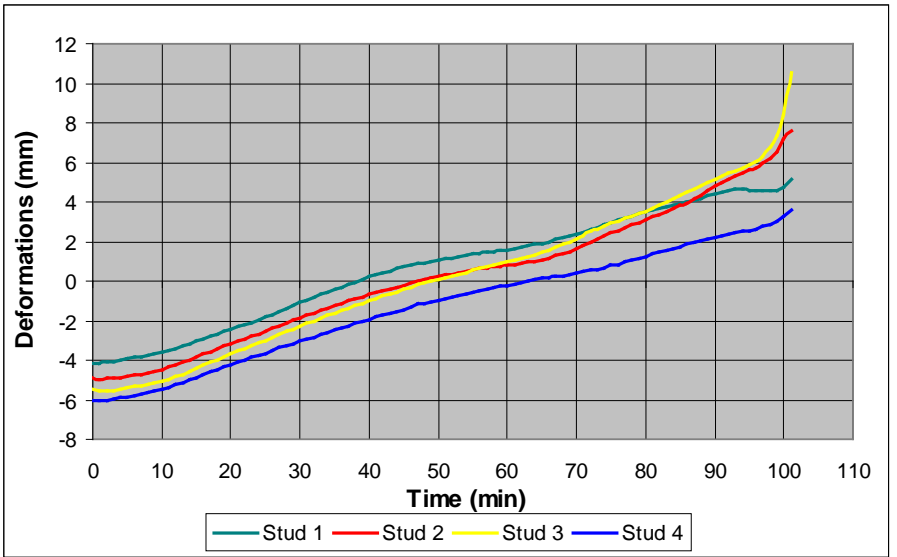

(c) Axial Deformation -Time Profiles of Studs

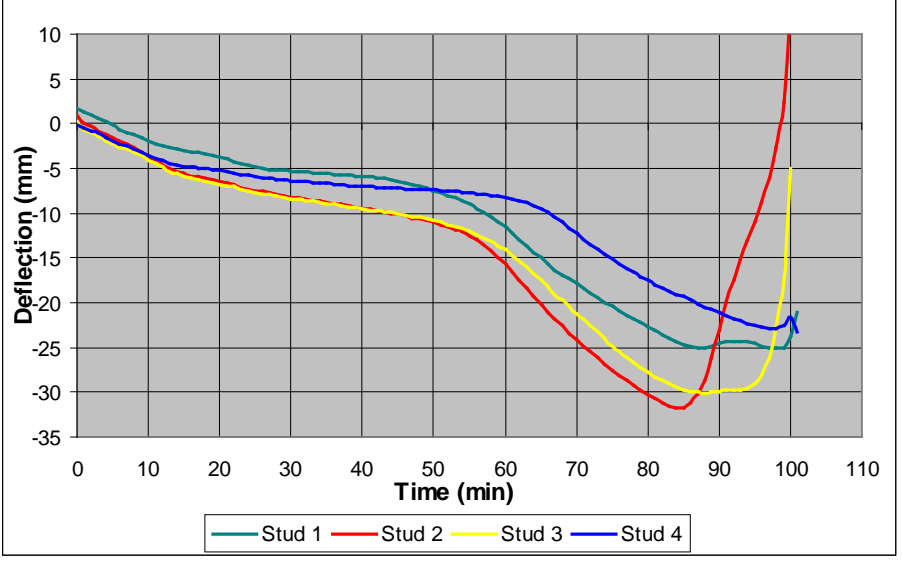

(d) Lateral Deflection -Time Profiles of Studs at Mid-height

Figure 10: Results for Test Specimen 4 


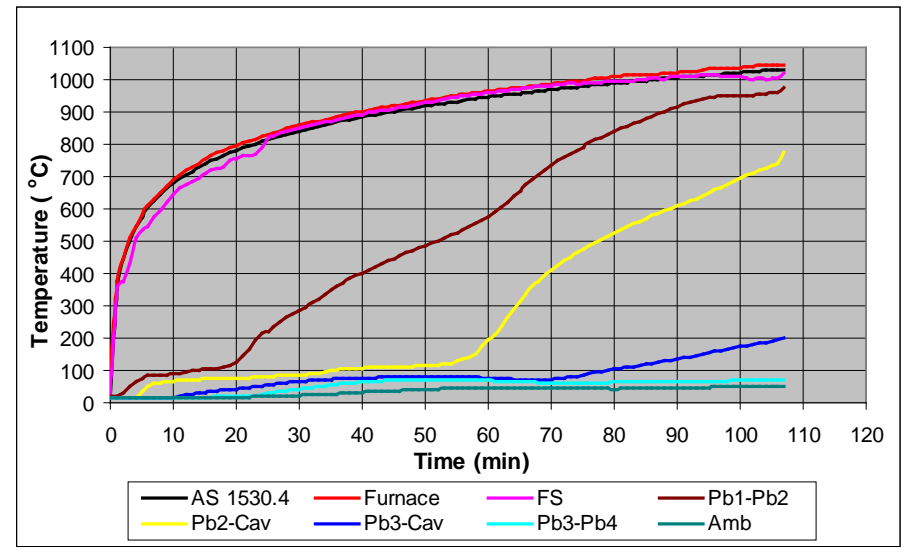

(a) Average Time-Temperature Profiles of Plasterboard Surfaces

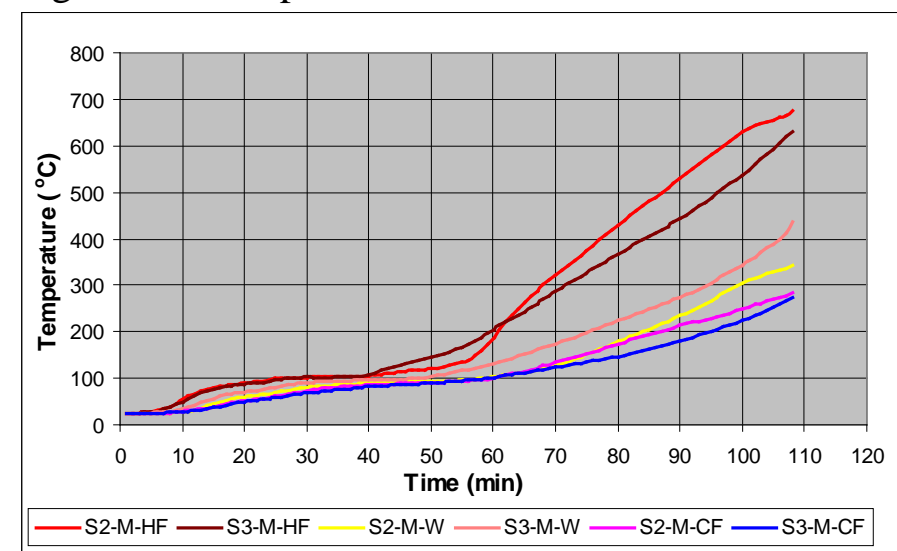

(b) Time-Temperature Profiles across Central Studs at Mid-Height

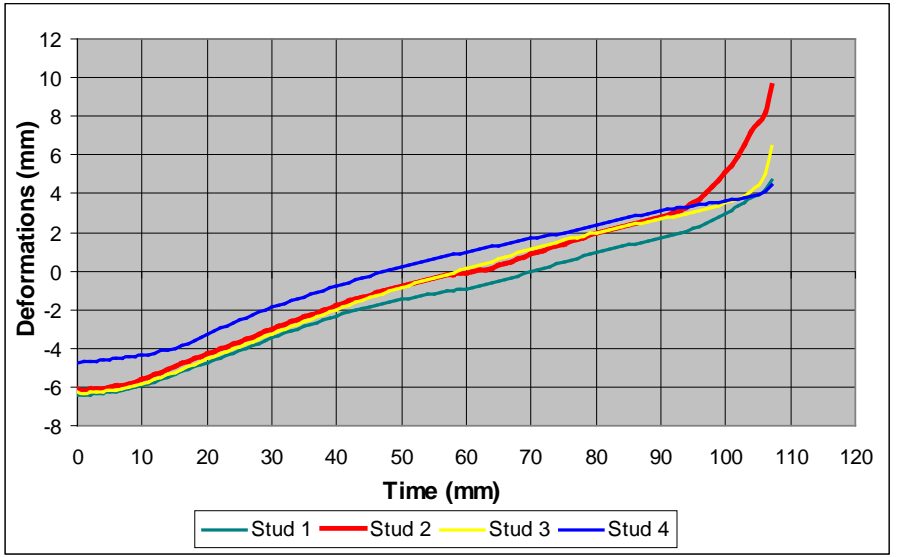

(c) Axial Deformation -Time Profiles of Studs

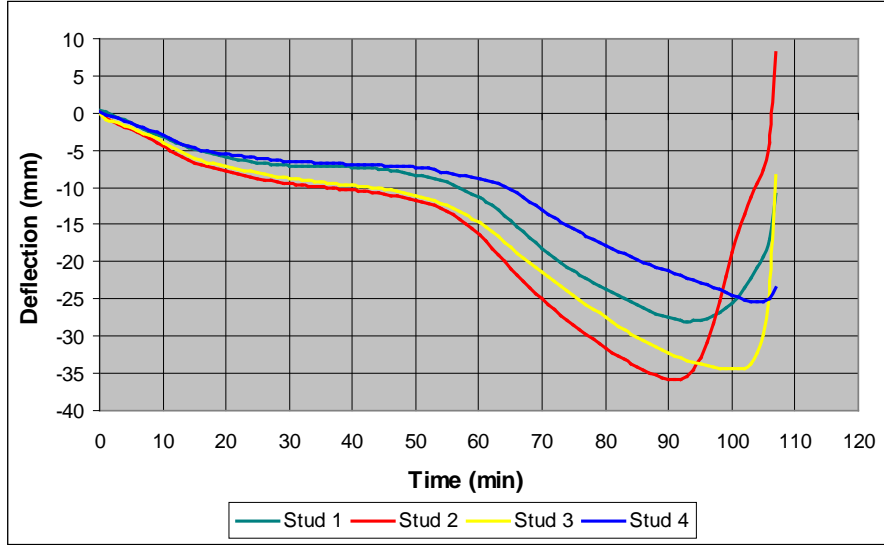

(d) Lateral Deflection -Time Profiles of Studs at Mid-height

Figure 11: Results for Test Specimen 5 


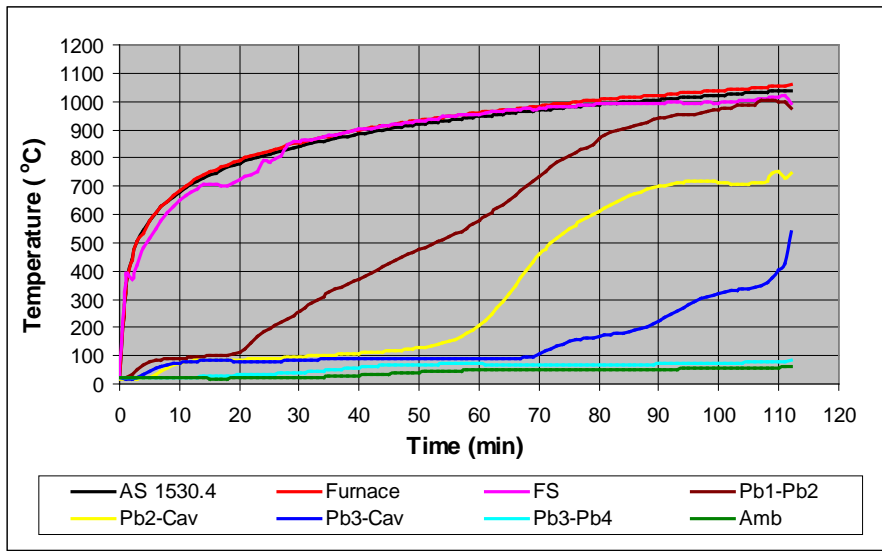

(a) Average Time-Temperature Profiles of Plasterboard Surfaces

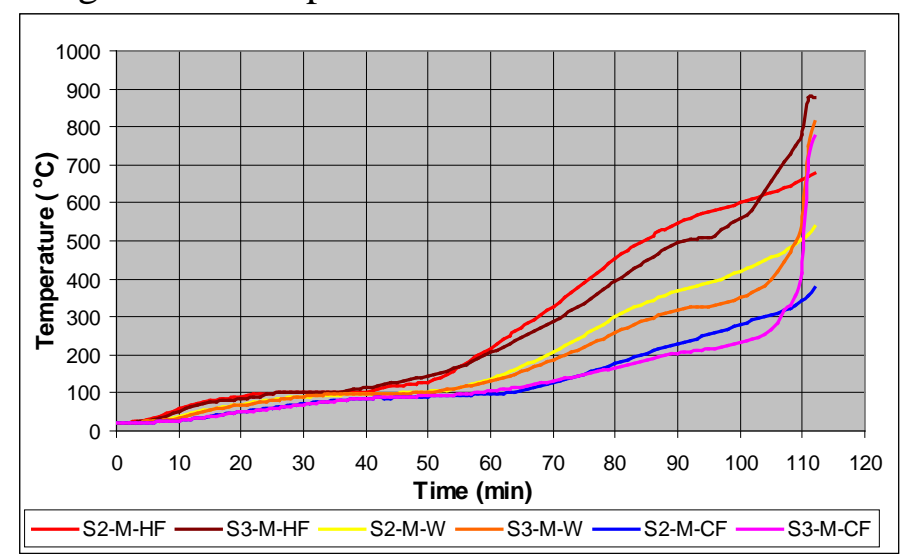

(b) Time-Temperature Profiles across Central Studs at Mid-Height

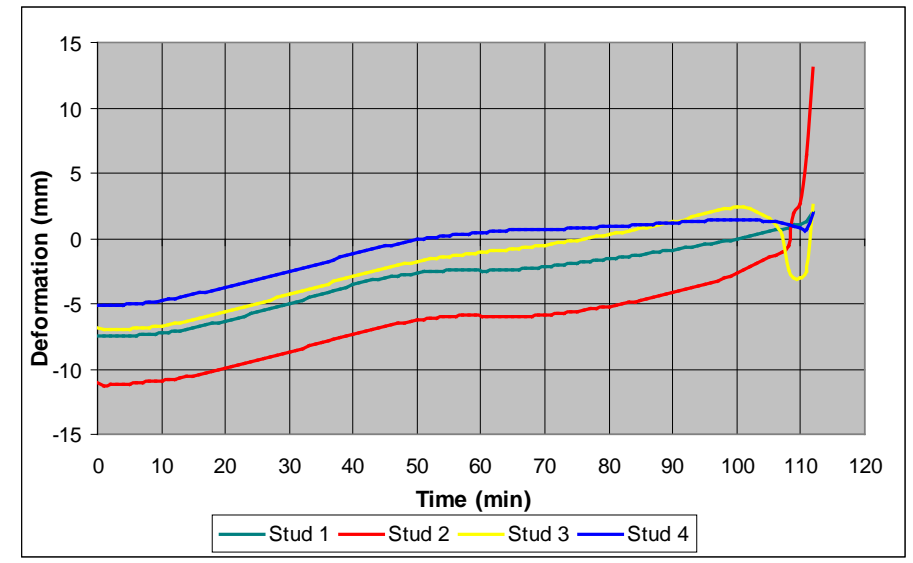

(c) Axial Deformation -Time Profiles of Studs

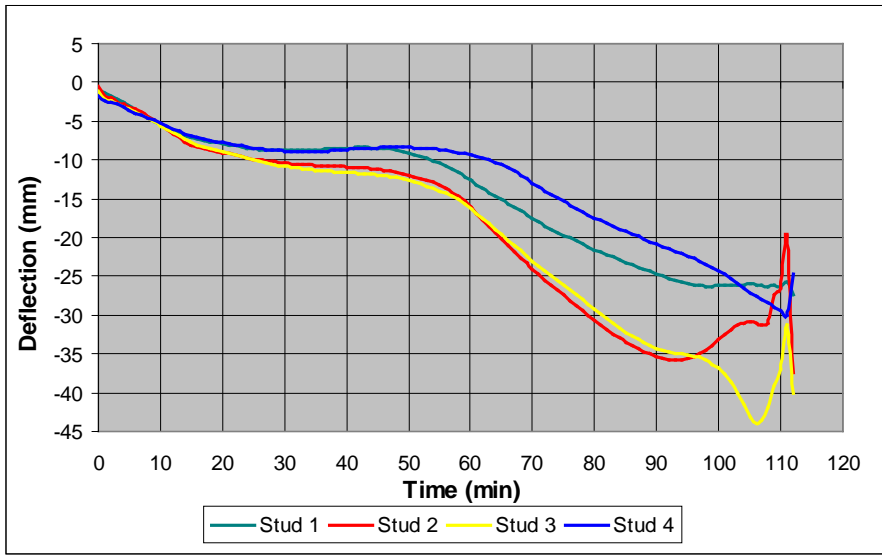

(d) Lateral Deflection -Time Profiles of Studs at Mid-height

Figure 12: Results for Test Specimen 6 


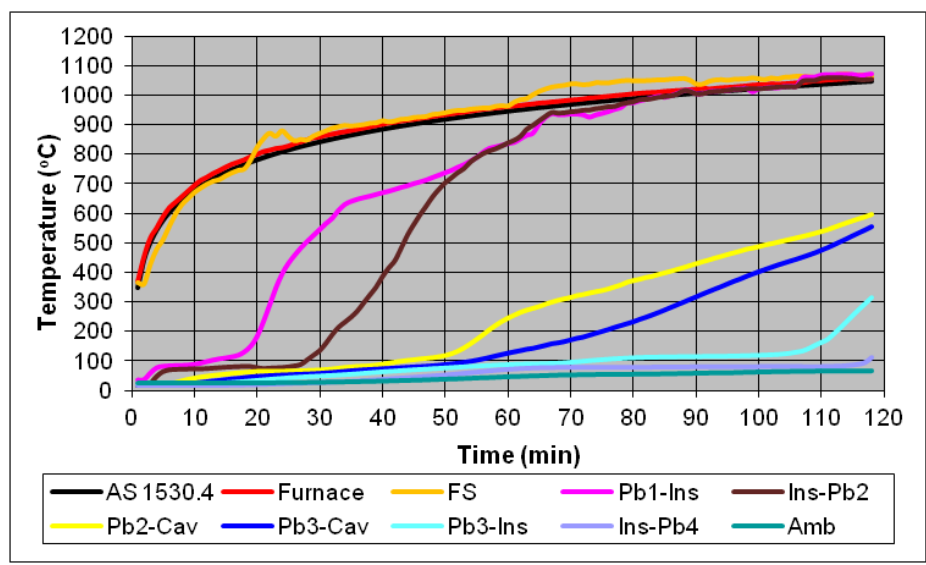

(a) Average Time-Temperature Profiles of Plasterboard Surfaces

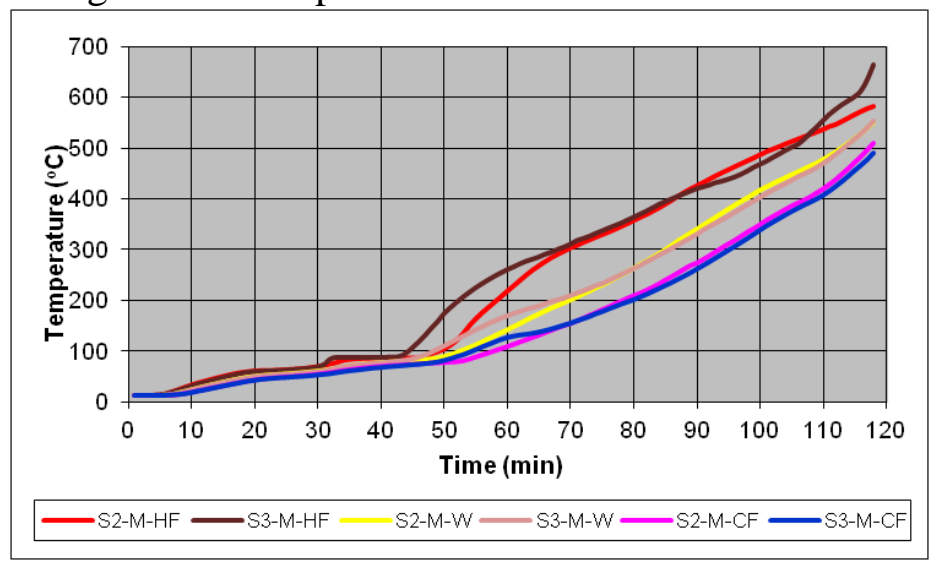

(b) Time-Temperature Profiles across Central Studs at Mid-Height

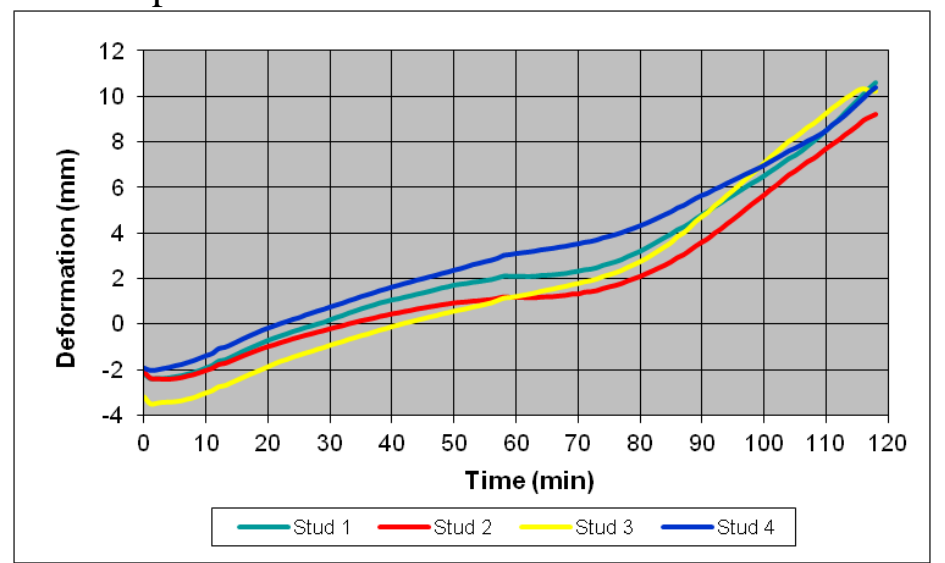

(c) Axial Deformation -Time Profiles of Studs

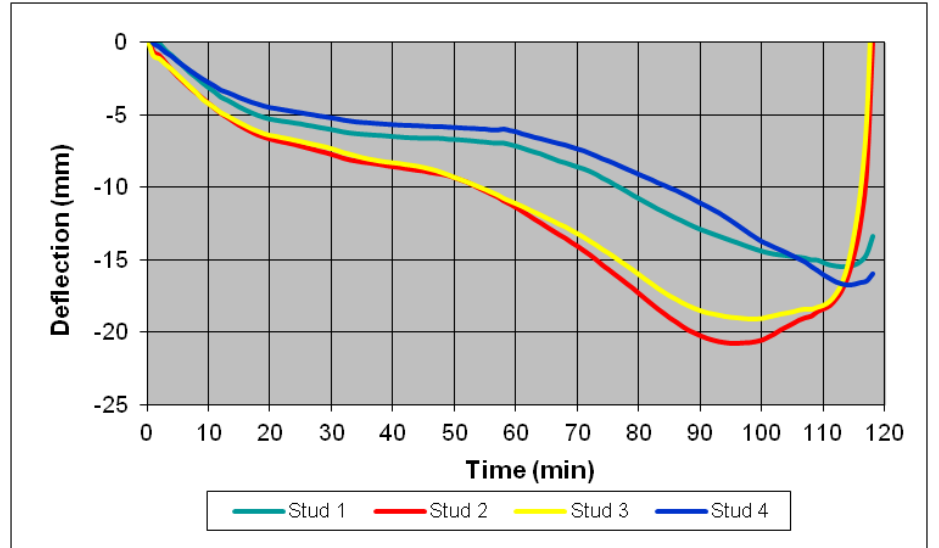

(d) Lateral Deflection -Time Profiles of Studs at Mid-height

Figure 13: Results for Test Specimen 7 


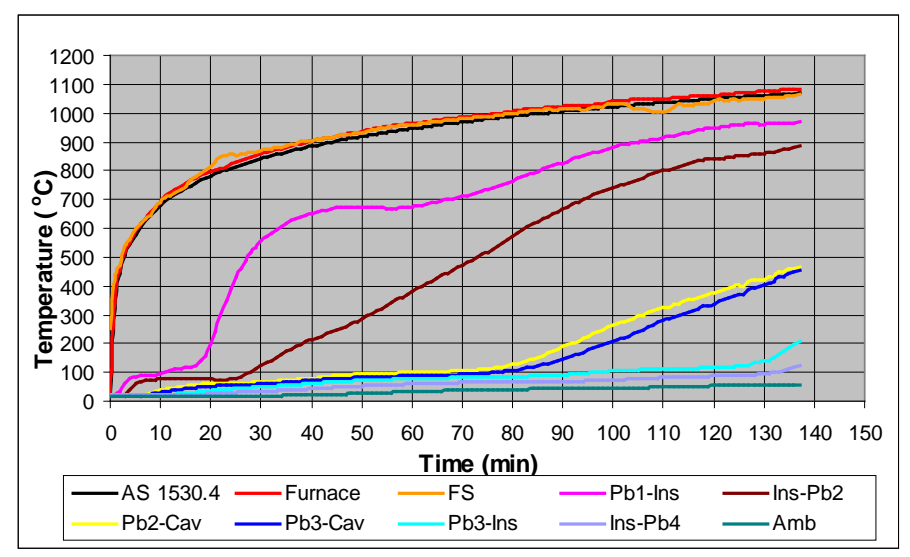

(a) Average Time-Temperature Profiles of Plasterboard Surfaces

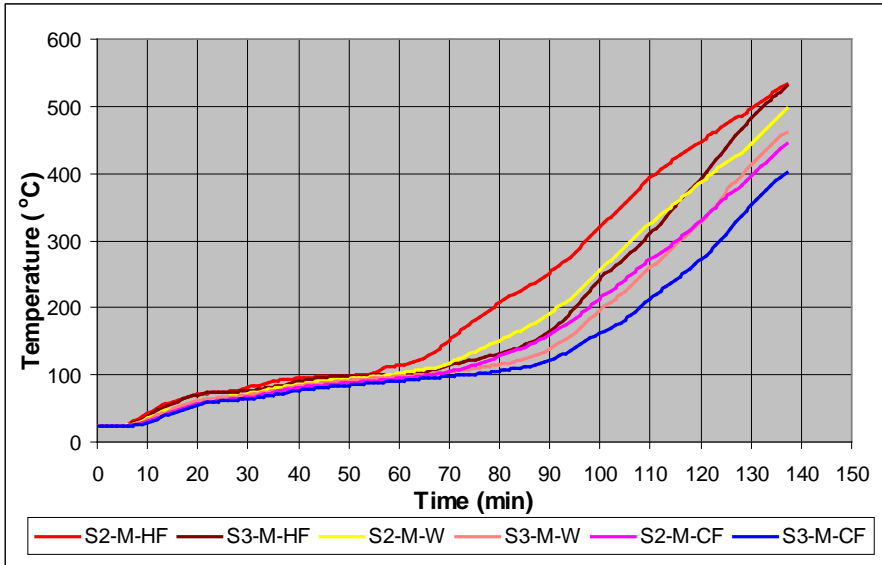

(b) Time-Temperature Profiles across Central Studs at Mid-height

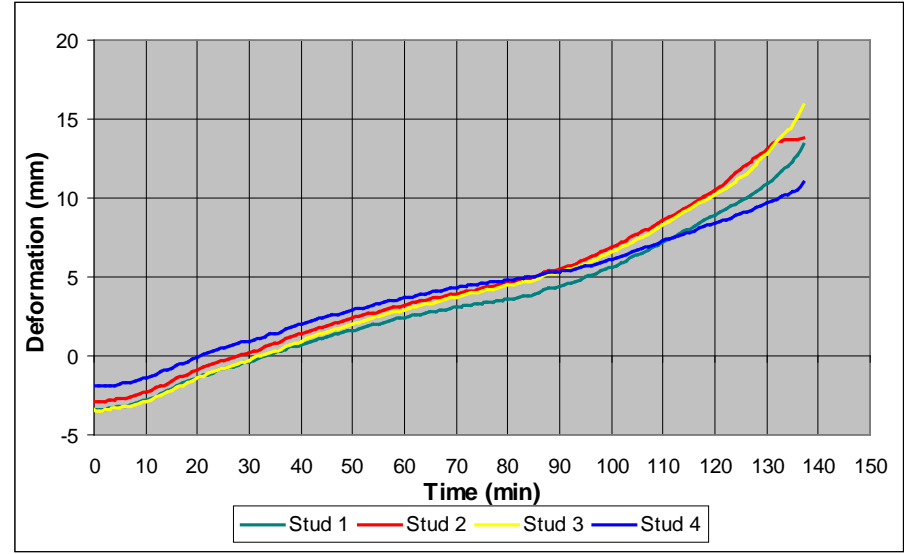

(c) Axial Deformation -Time Profiles of Studs

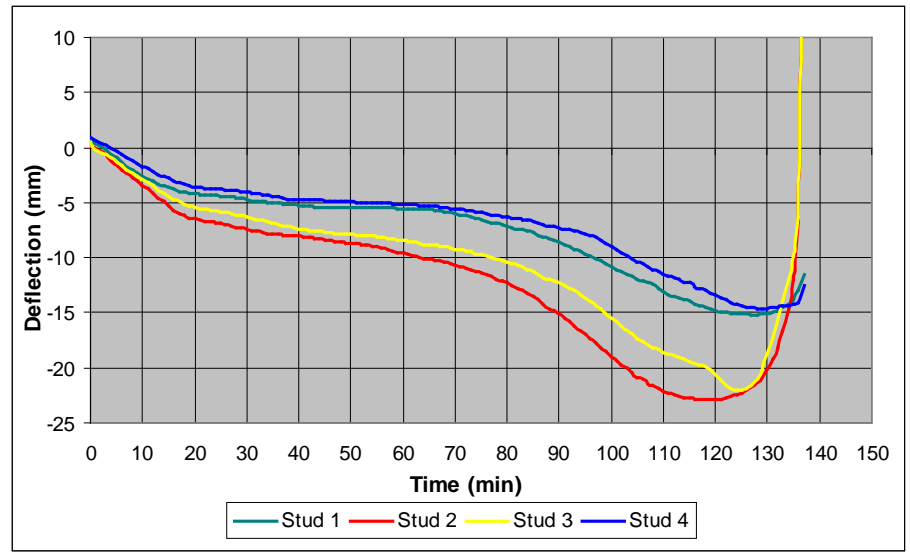

(d) Lateral Deflection -Time Profiles of Studs at Mid-height

Figure 14: Results for Test Specimen 8 


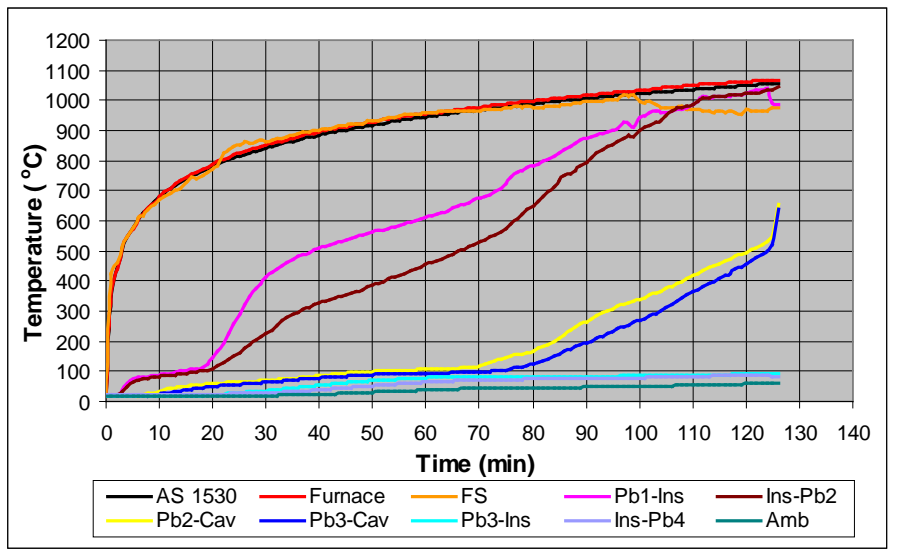

(a) Average Time-Temperature Profiles of Plasterboard Surfaces

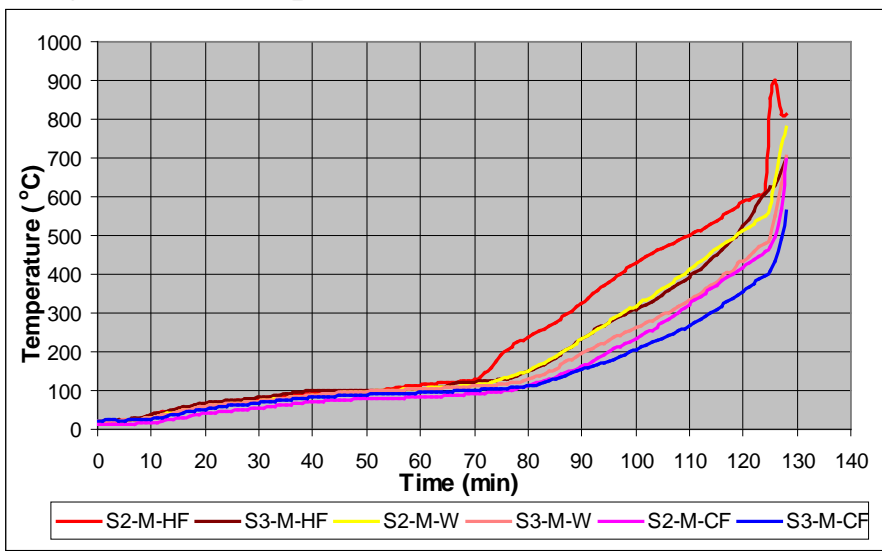

(b) Time-Temperature Profiles across Central Studs at Mid-height

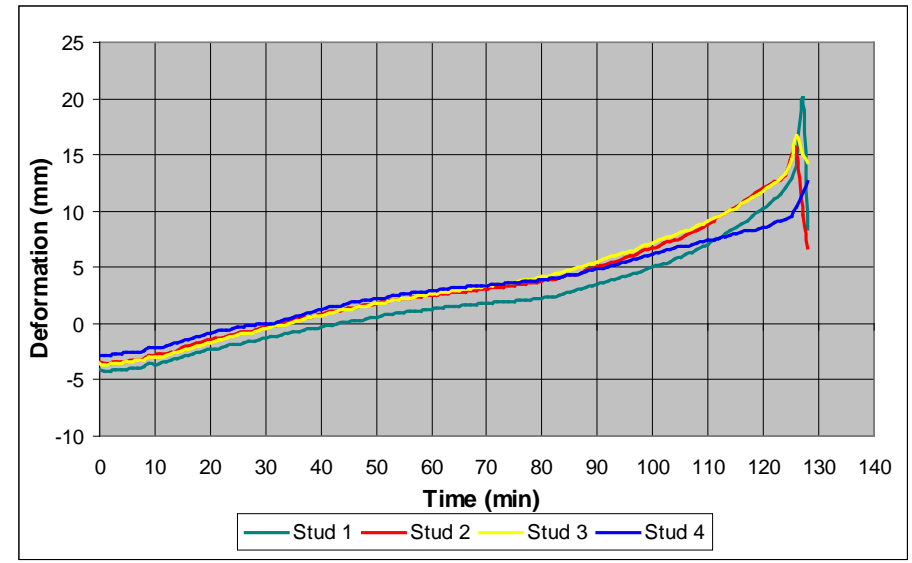

(c) Axial Deformation -Time Profiles of Studs

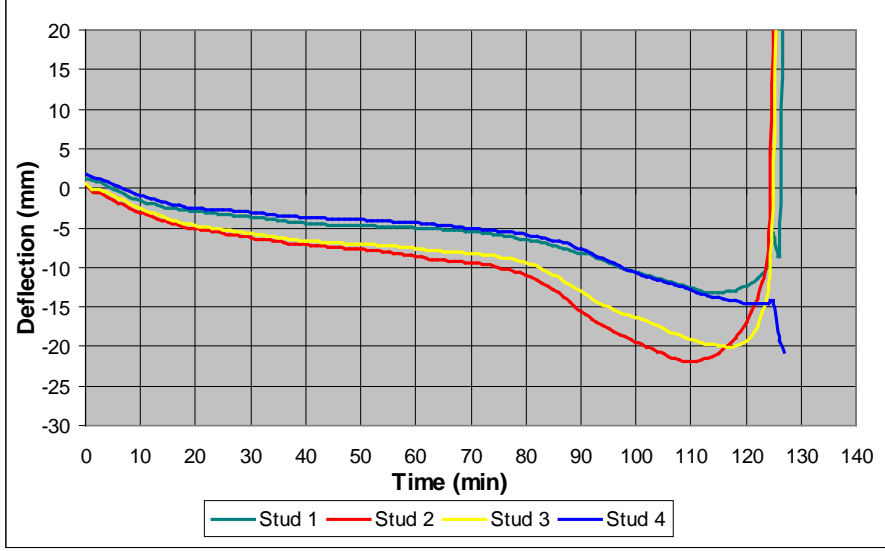

(d) Lateral Deflection -Time Profiles of Studs at Mid-height

Figure 15: Results for Test Specimen 9 


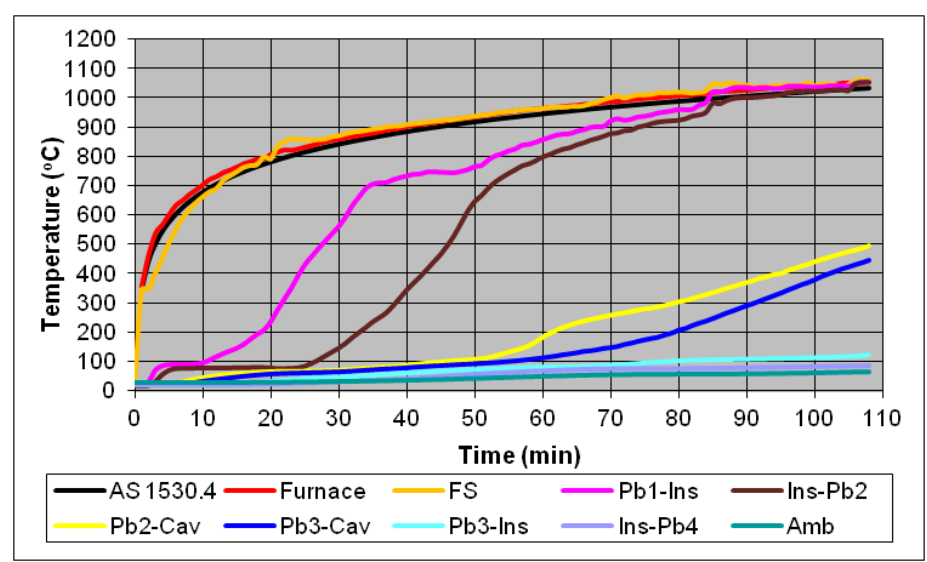

(a) Average Time-Temperature Profiles of Plasterboard Surfaces

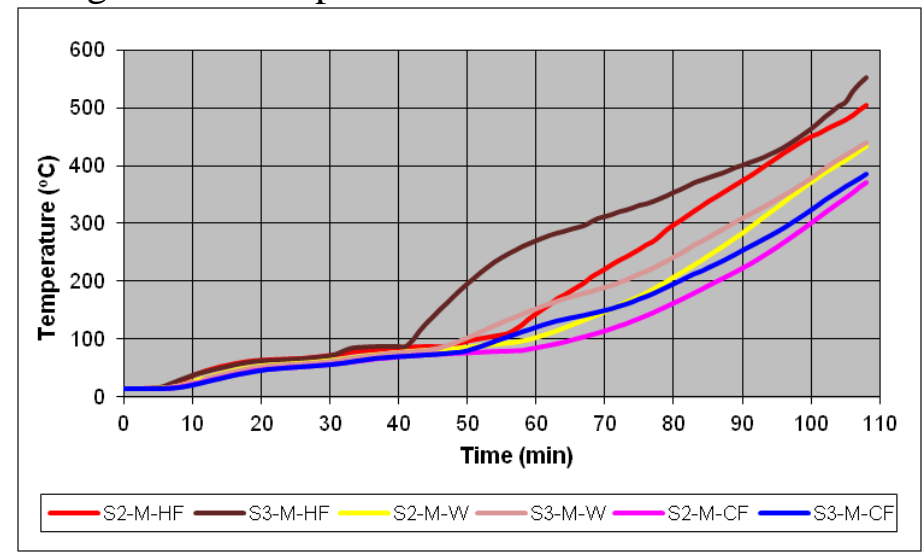

(b) Time-Temperature Profiles across Central Studs at Mid-height

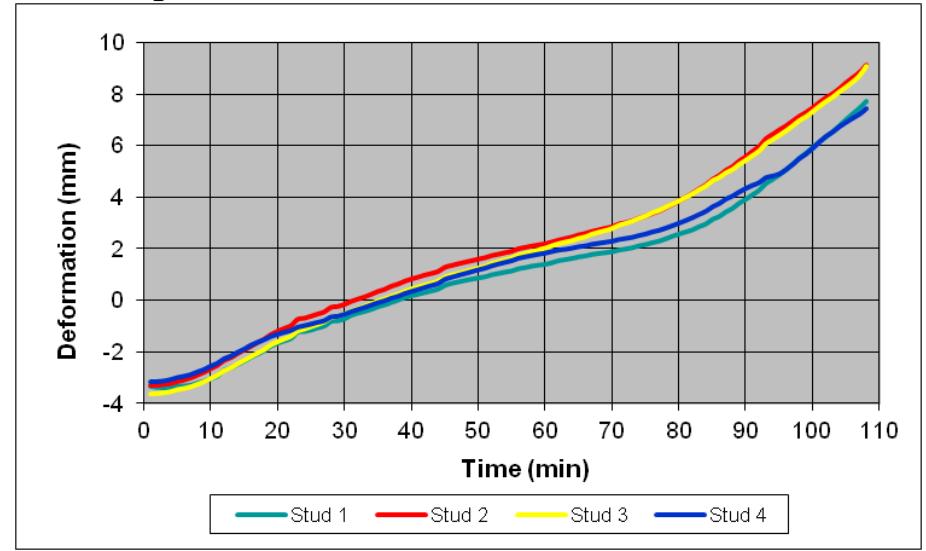

(c) Axial Deformation -Time Profiles of Studs

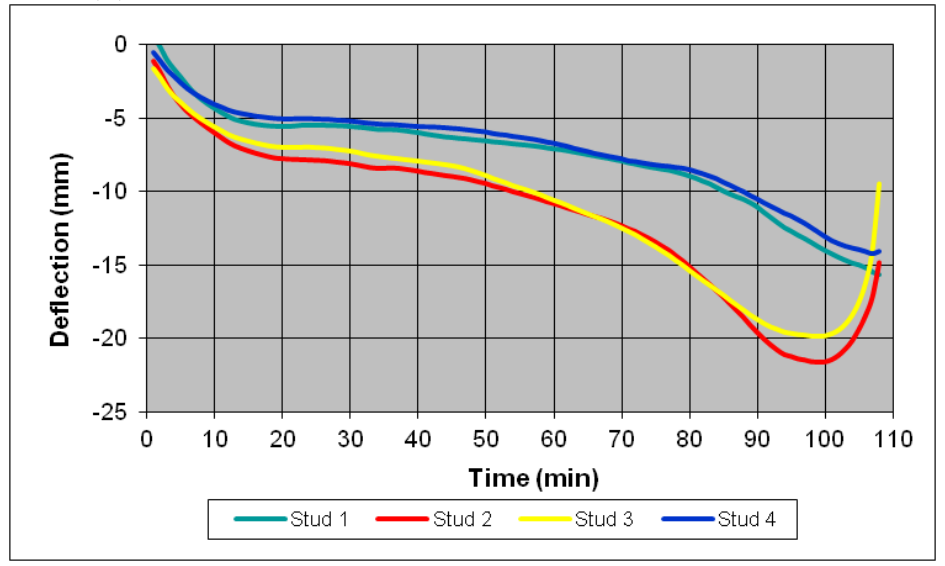

(d) Lateral Deflection -Time Profiles of Studs at Mid-height

Figure 16: Results for Test Specimen 10 


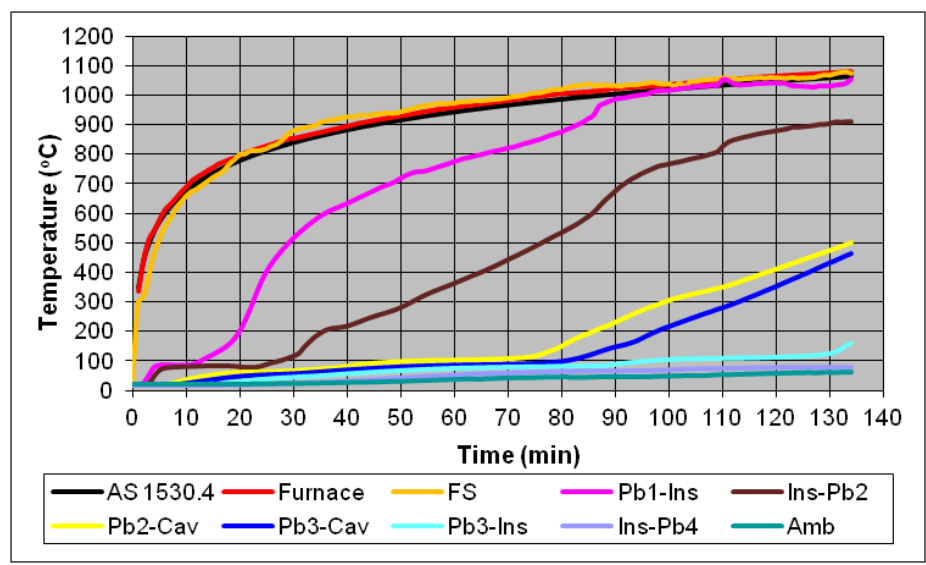

(a) Average Time-Temperature Profiles of Plasterboard Surfaces

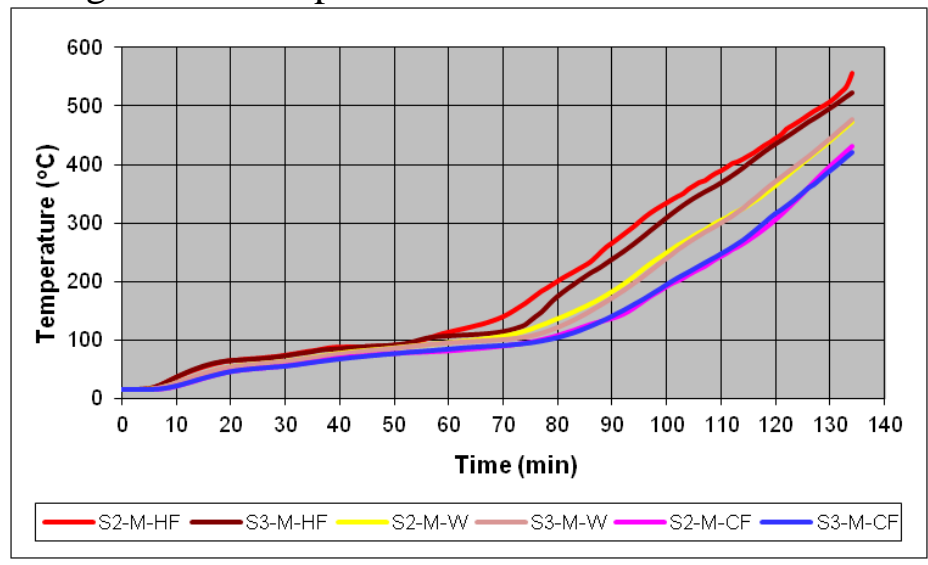

(b) Time-Temperature Profiles across Central Studs at Mid-height

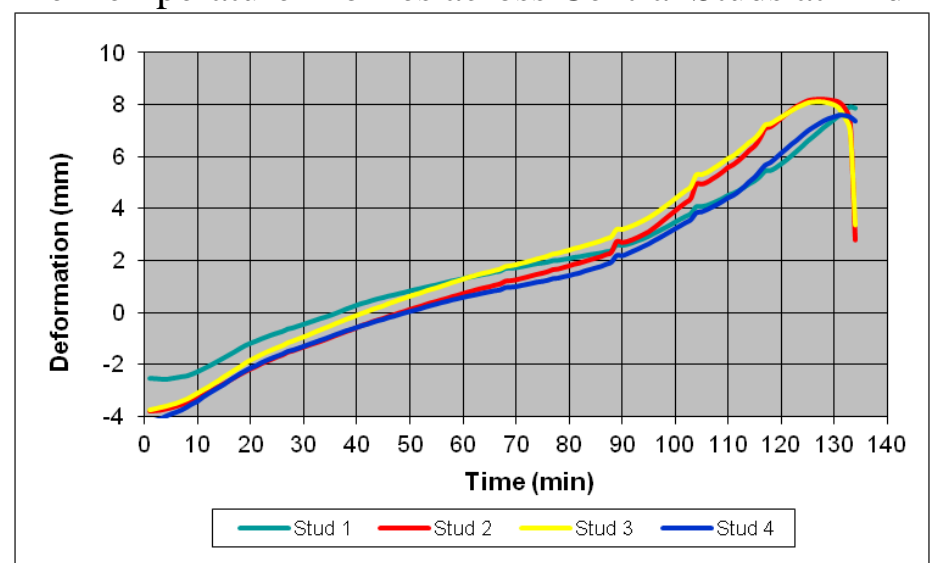

(c) Axial Deformation -Time Profiles of Studs

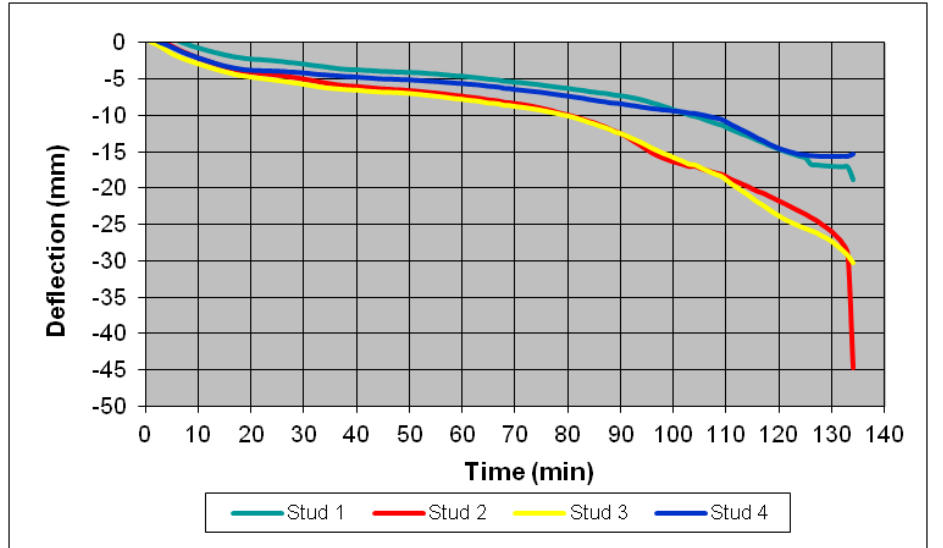

(d) Lateral Deflection -Time Profiles of Studs at Mid-height

Figure 17: Results for Test Specimen 11 


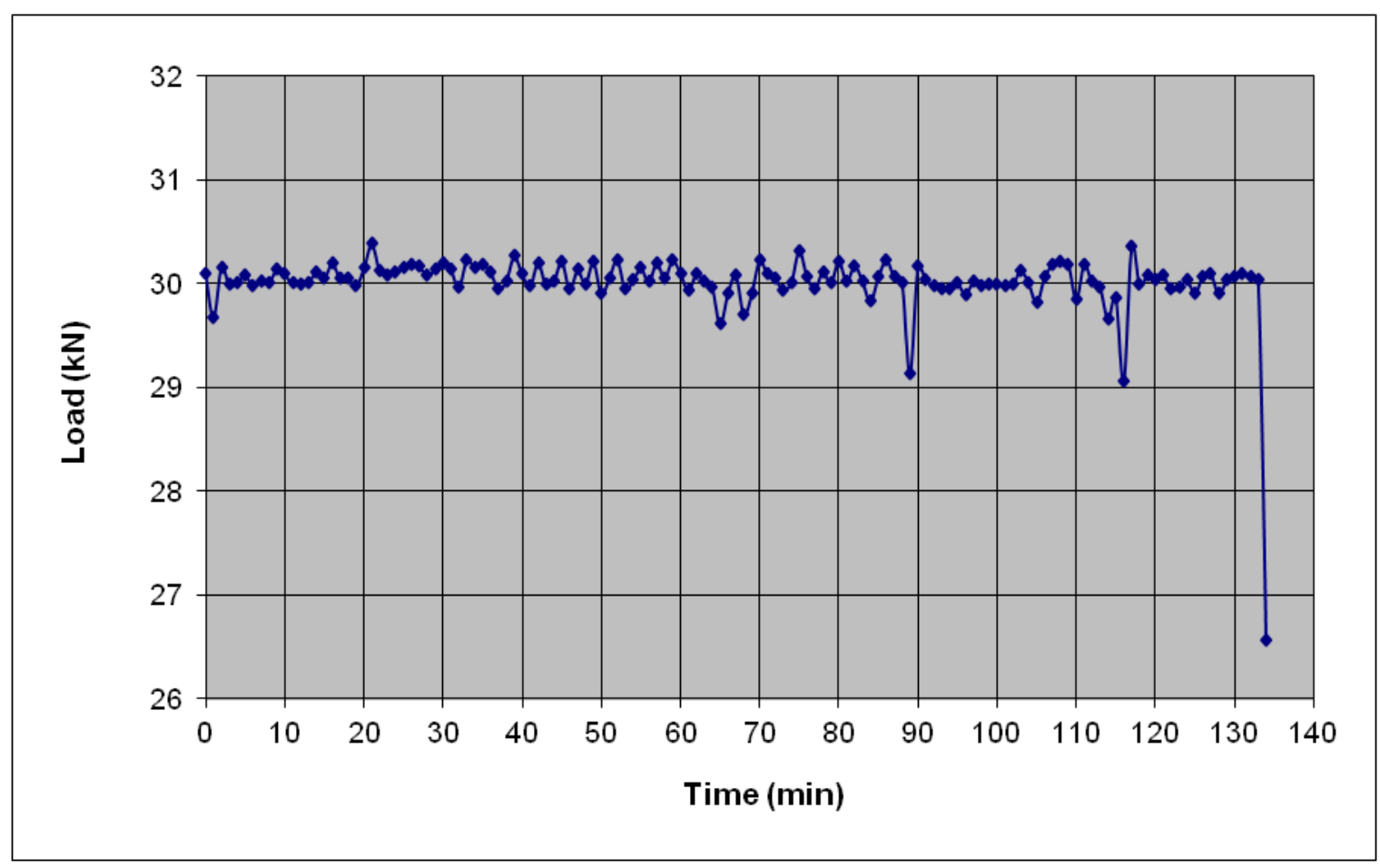

Figure 18: Axial Compression Load - Time Curve of Test Specimen 11 

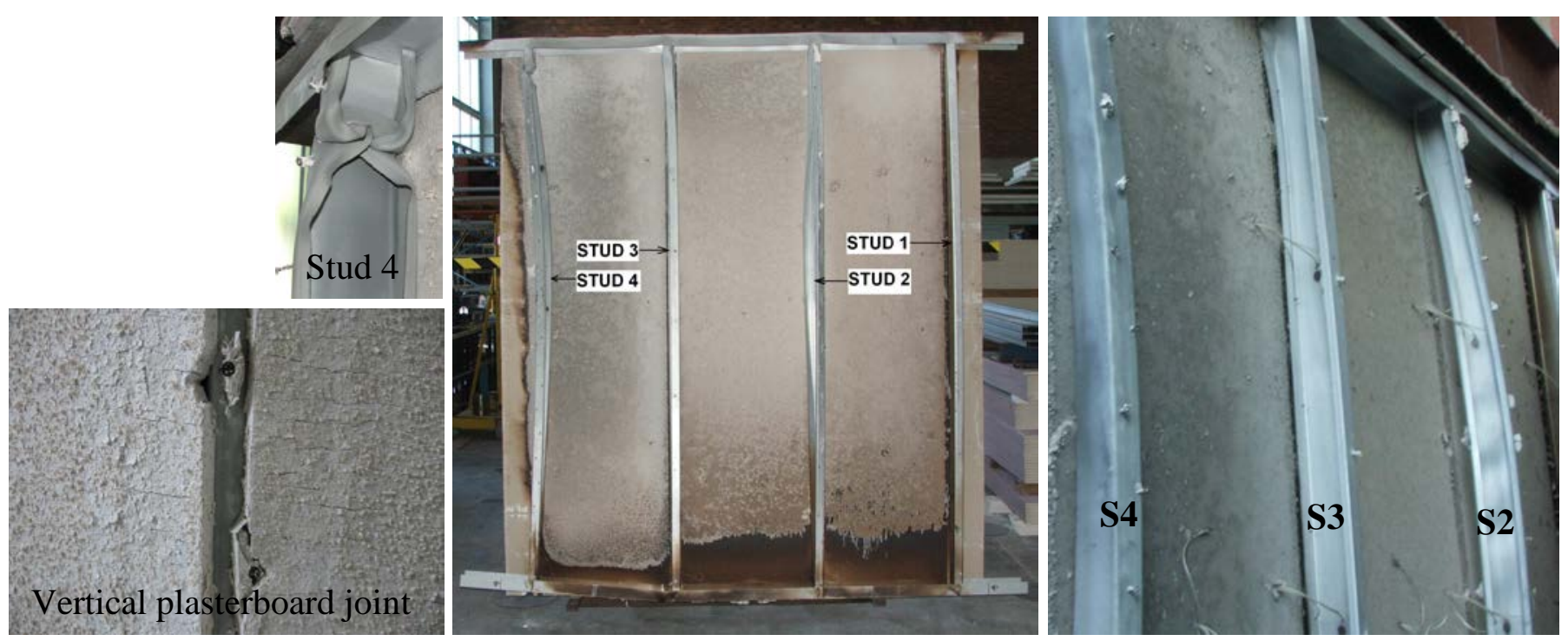

(a) Test Specimen 2
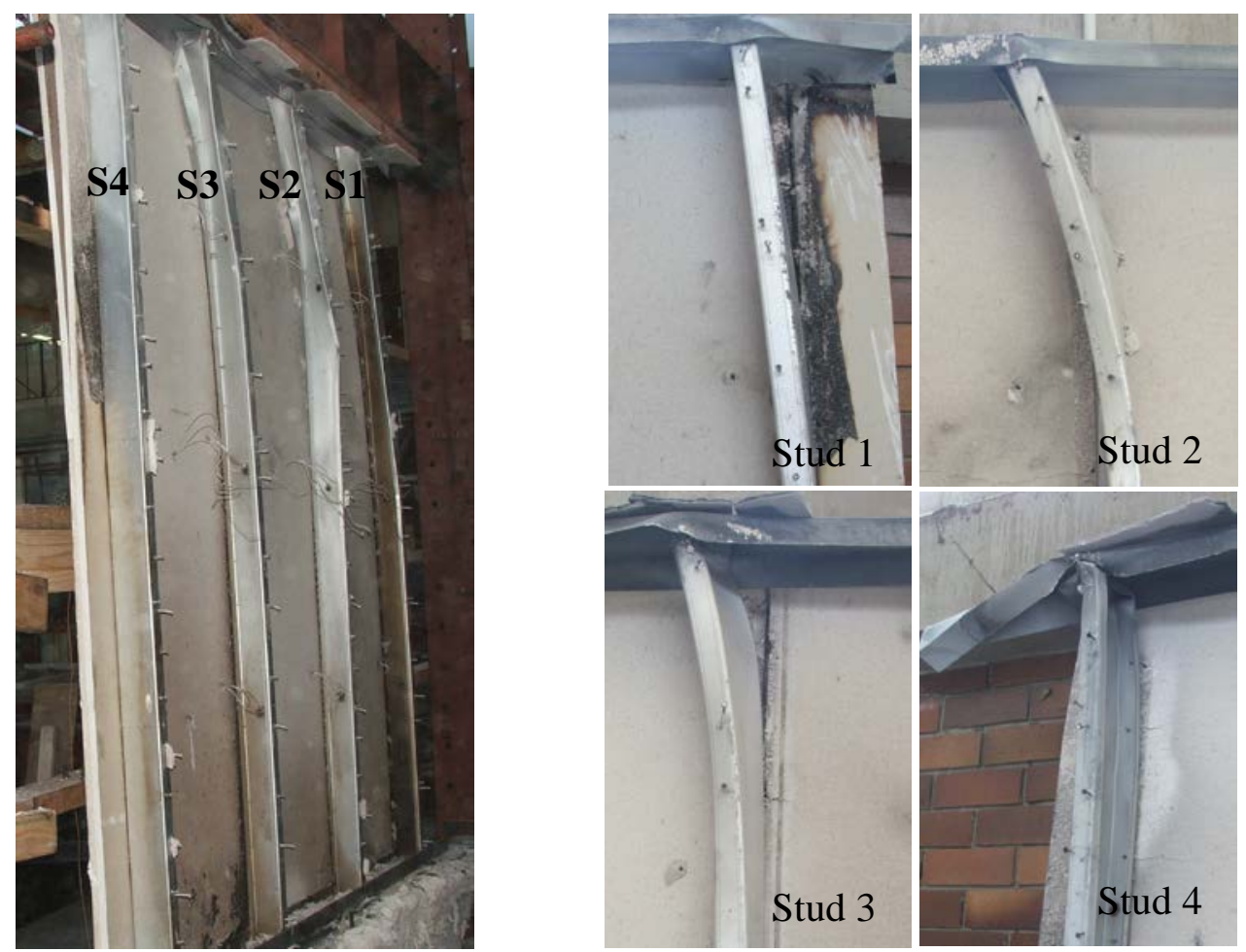

(b) Test Specimen 3

Figure 19: Test Specimens 2 and 3 after Removing the Exposed Side Plasterboards 


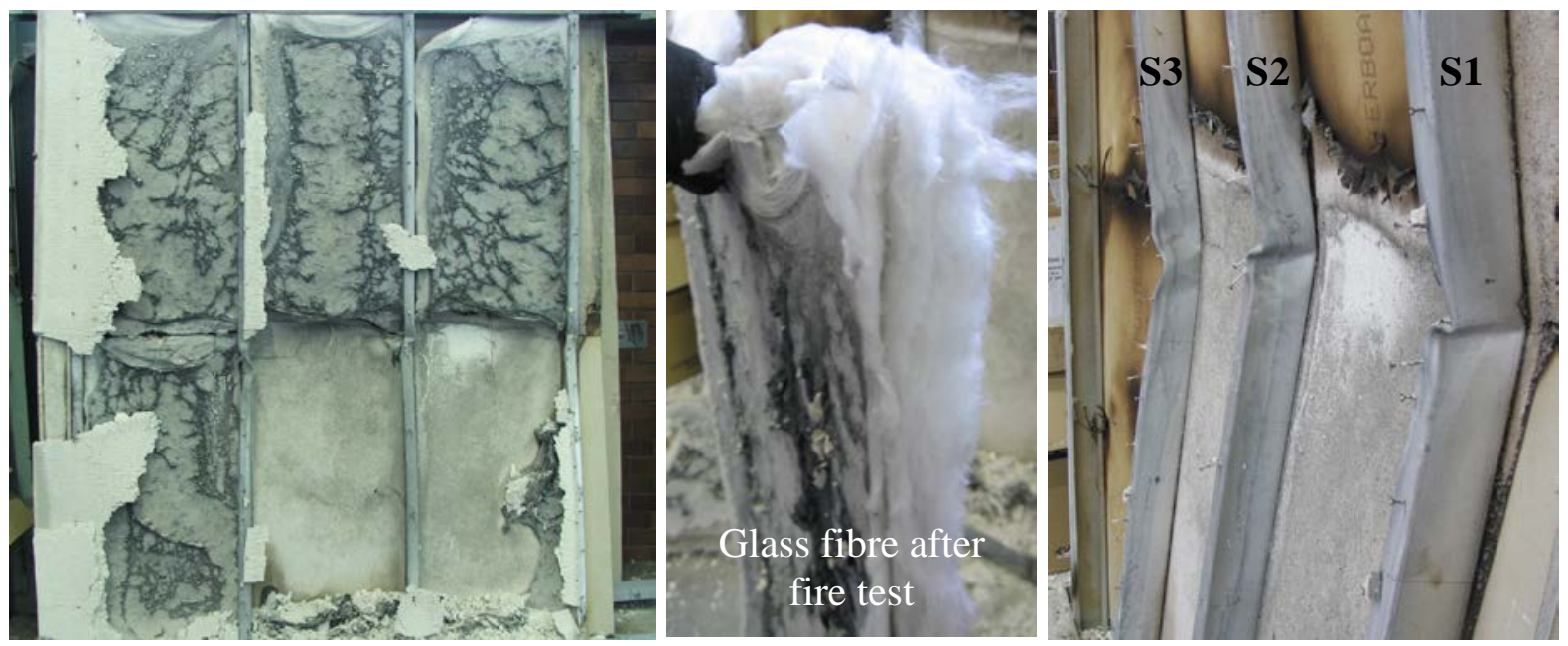

(a) Test Specimen 4

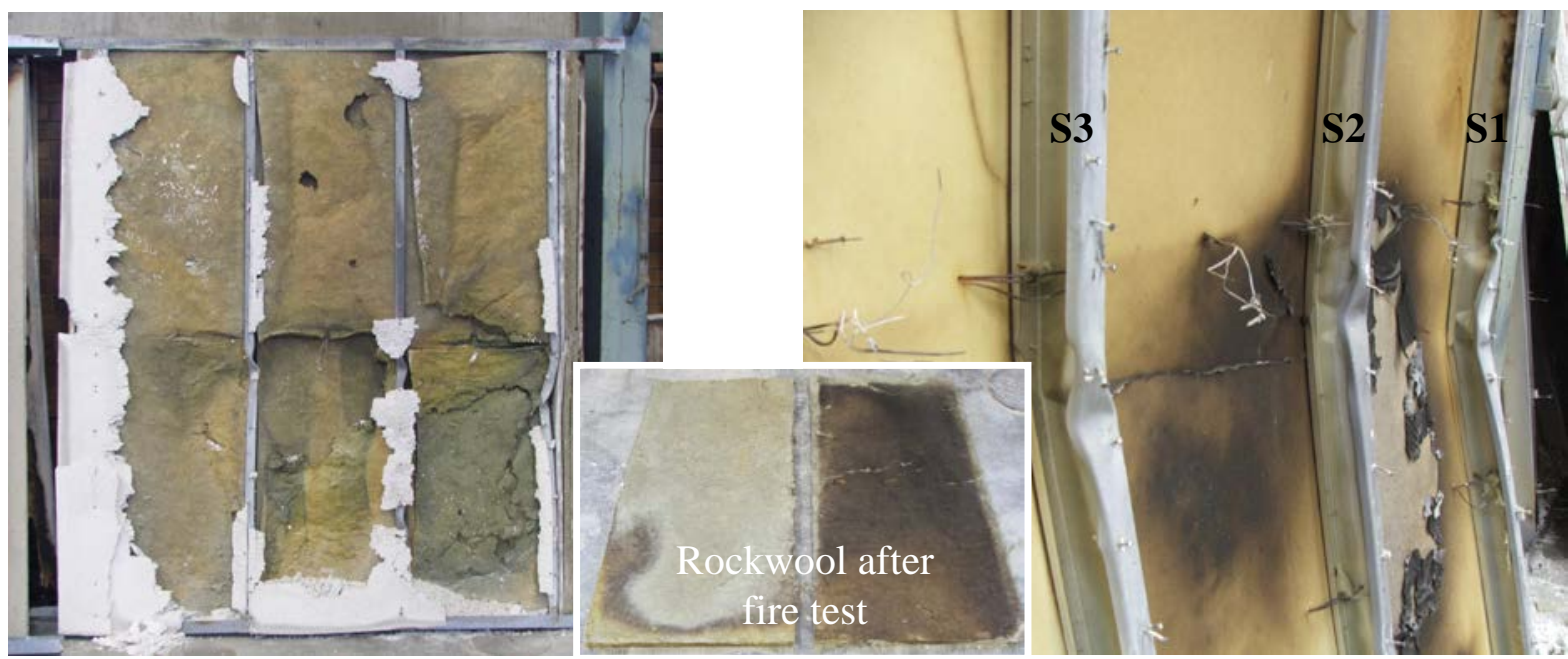

(b) Test Specimen 5
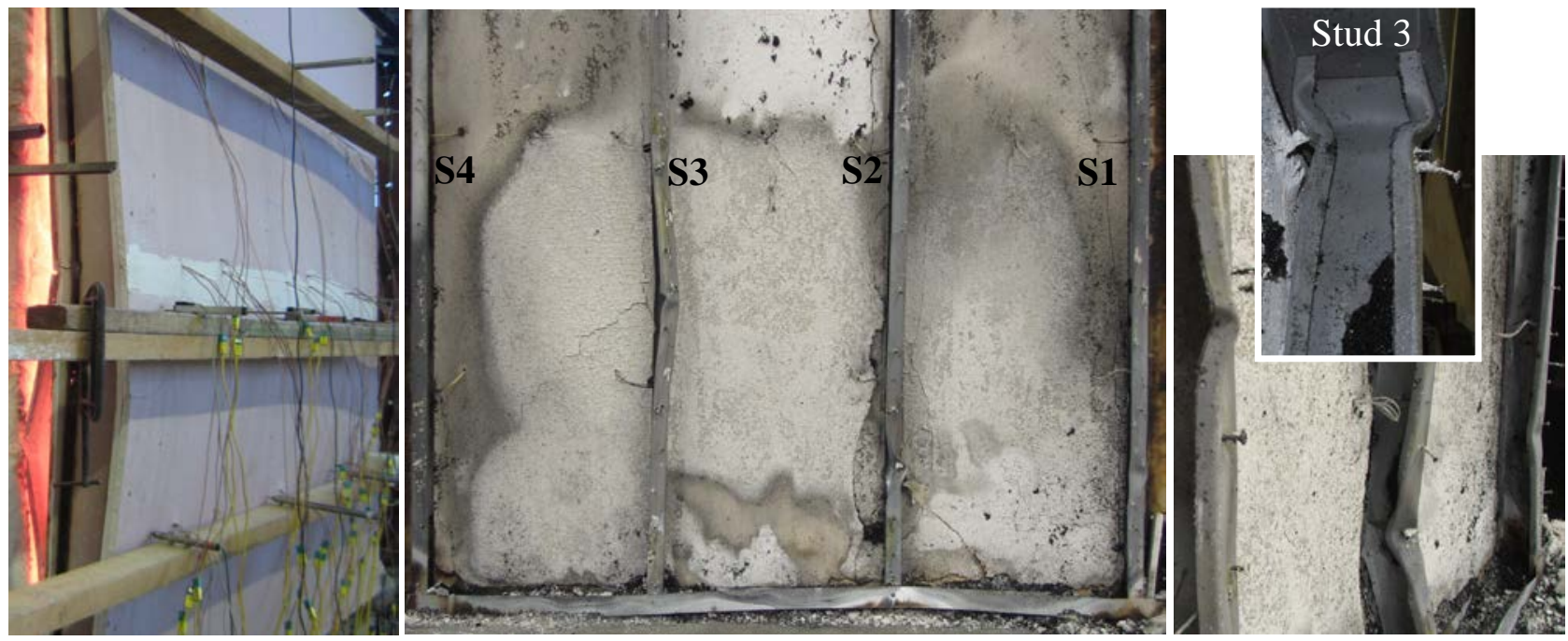

(c) Test Specimen 6

Figure 20: Test Specimens 4 to 6 after the Fire Tests 

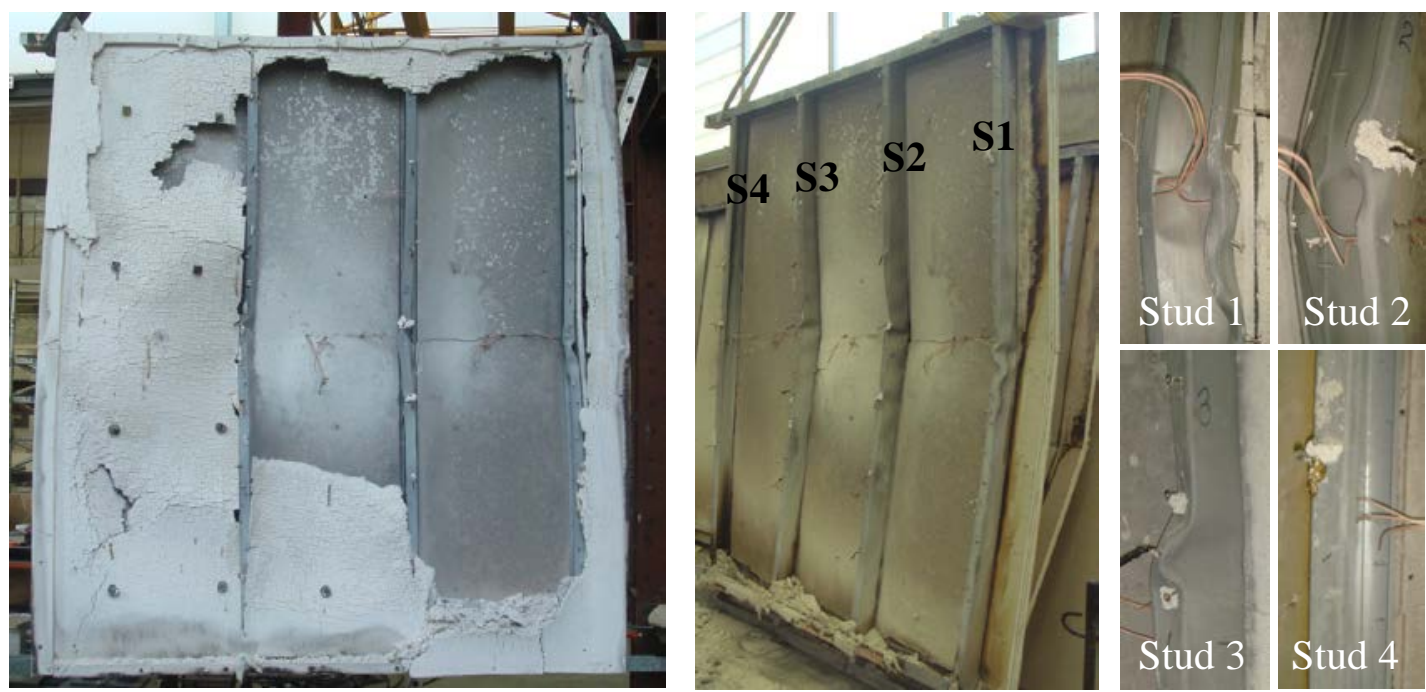

(a) Test Specimen 7
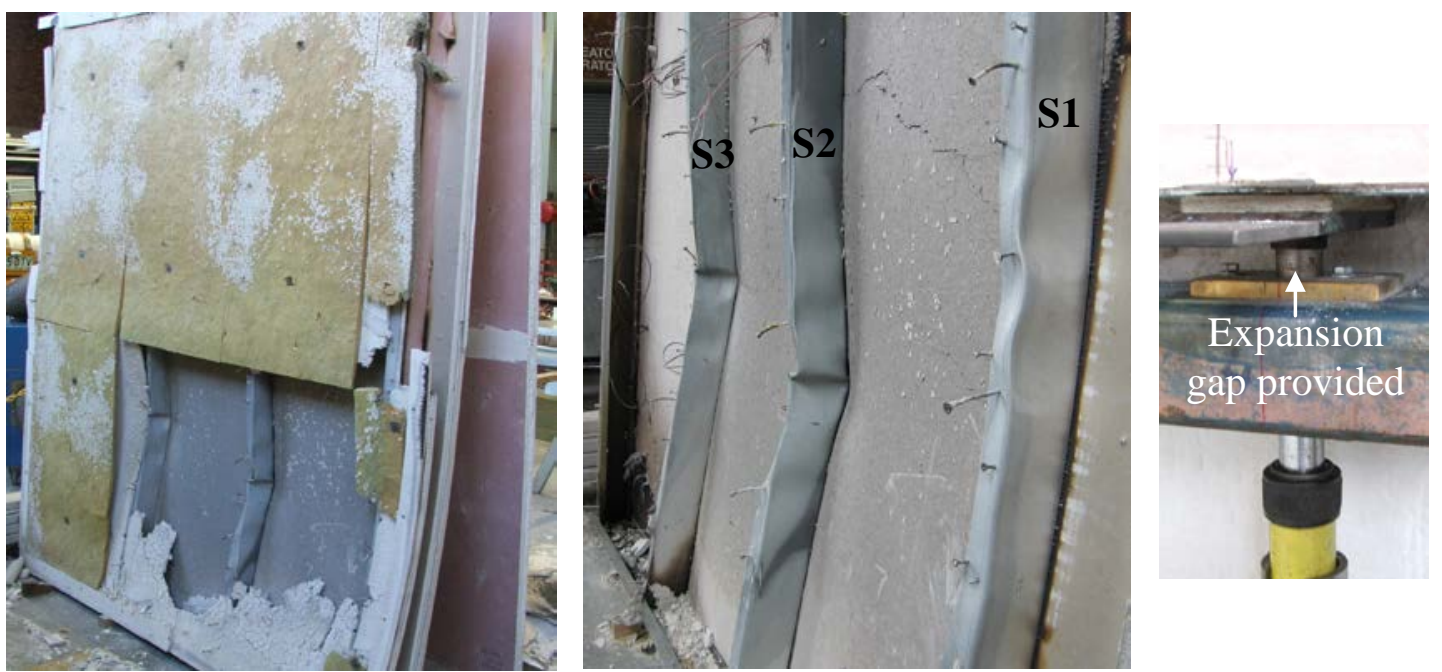

(b) Test Specimen 8
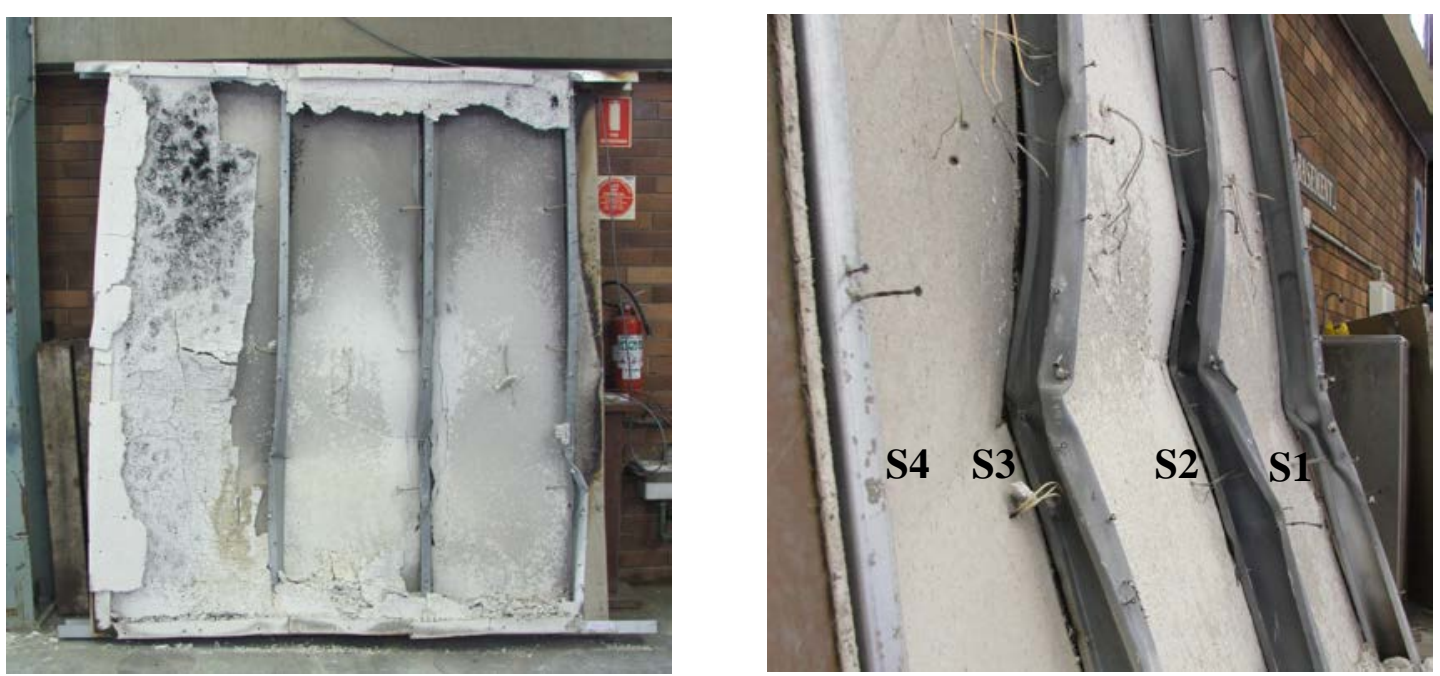

(c) Test Specimen 9

Figure 21: Test Specimens 7 to 9 after the Fire Tests 

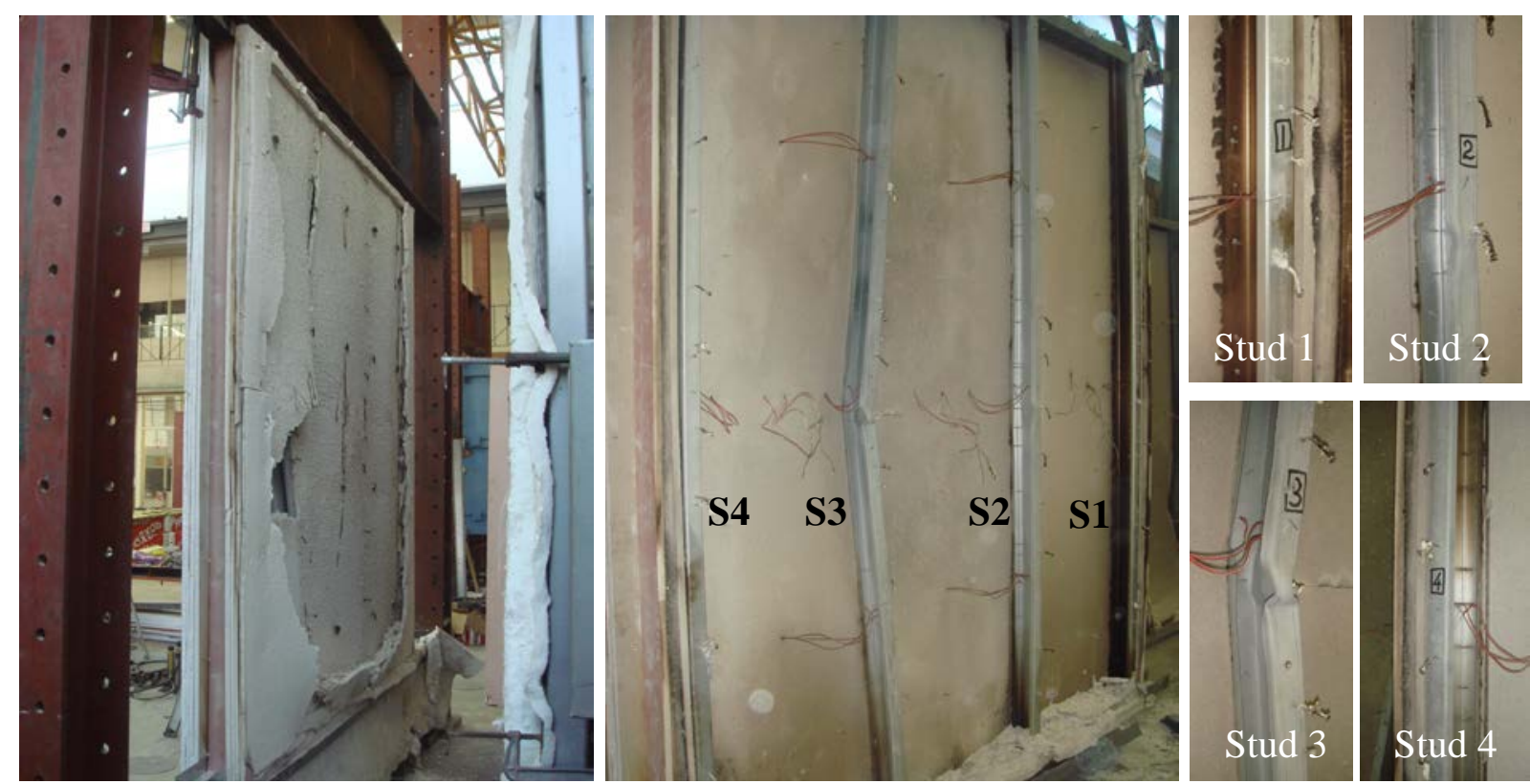

(a) Test Specimen 10

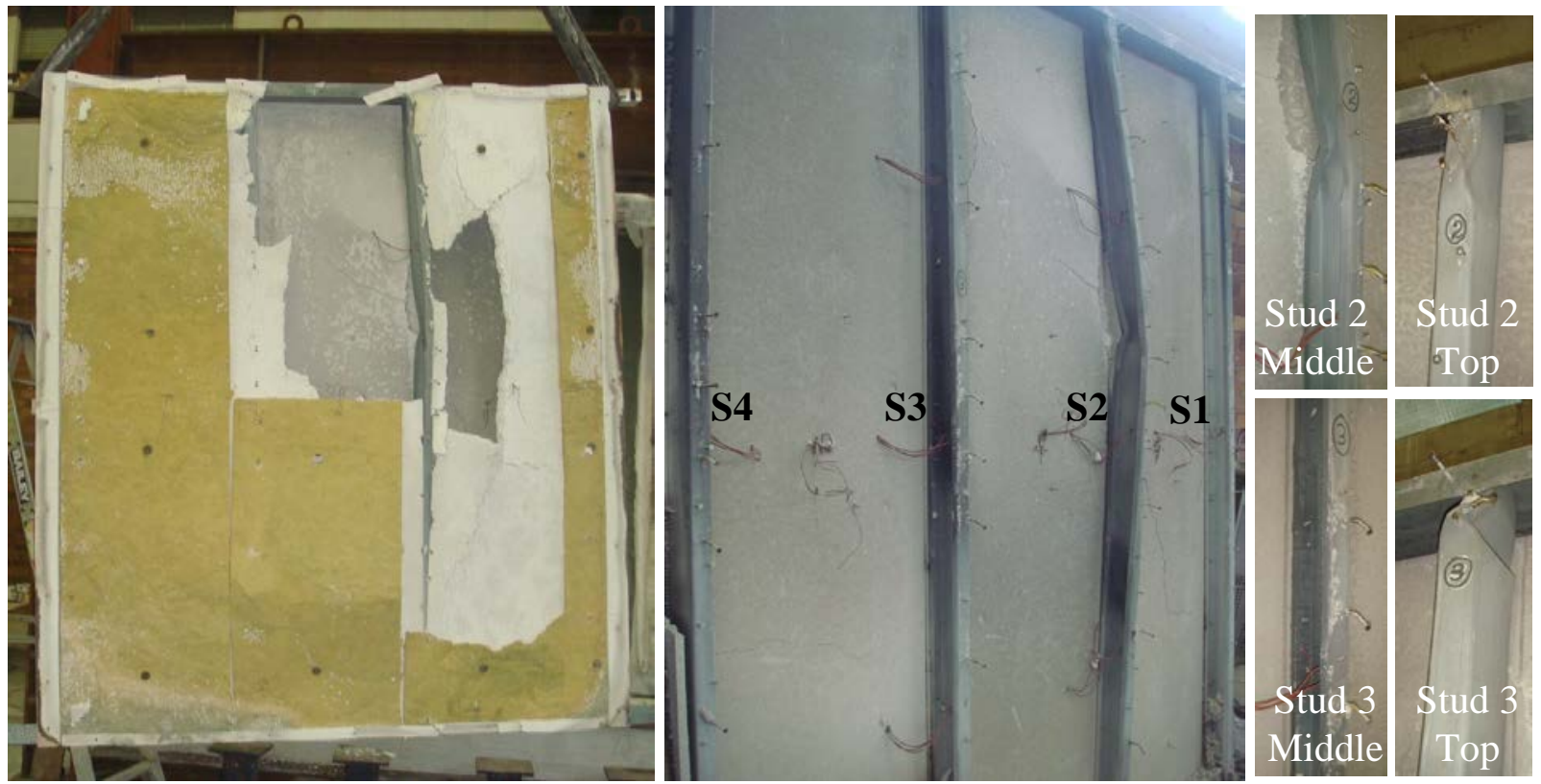

(b) Test Specimen 11

Figure 22: Test Specimens 10 and 11 after the Fire Tests 


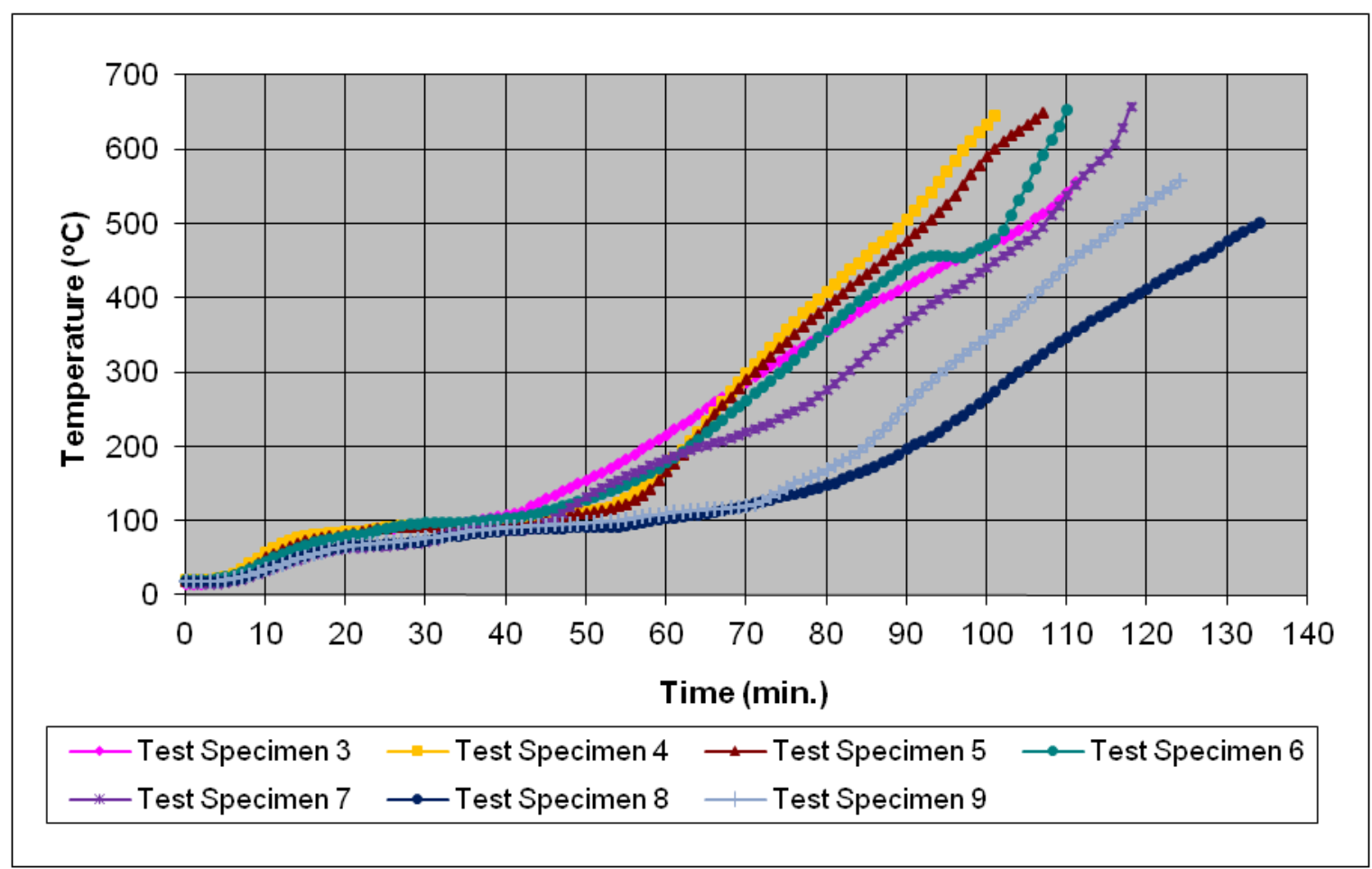

(a) Average Time-temperature Profiles of Hot Flange

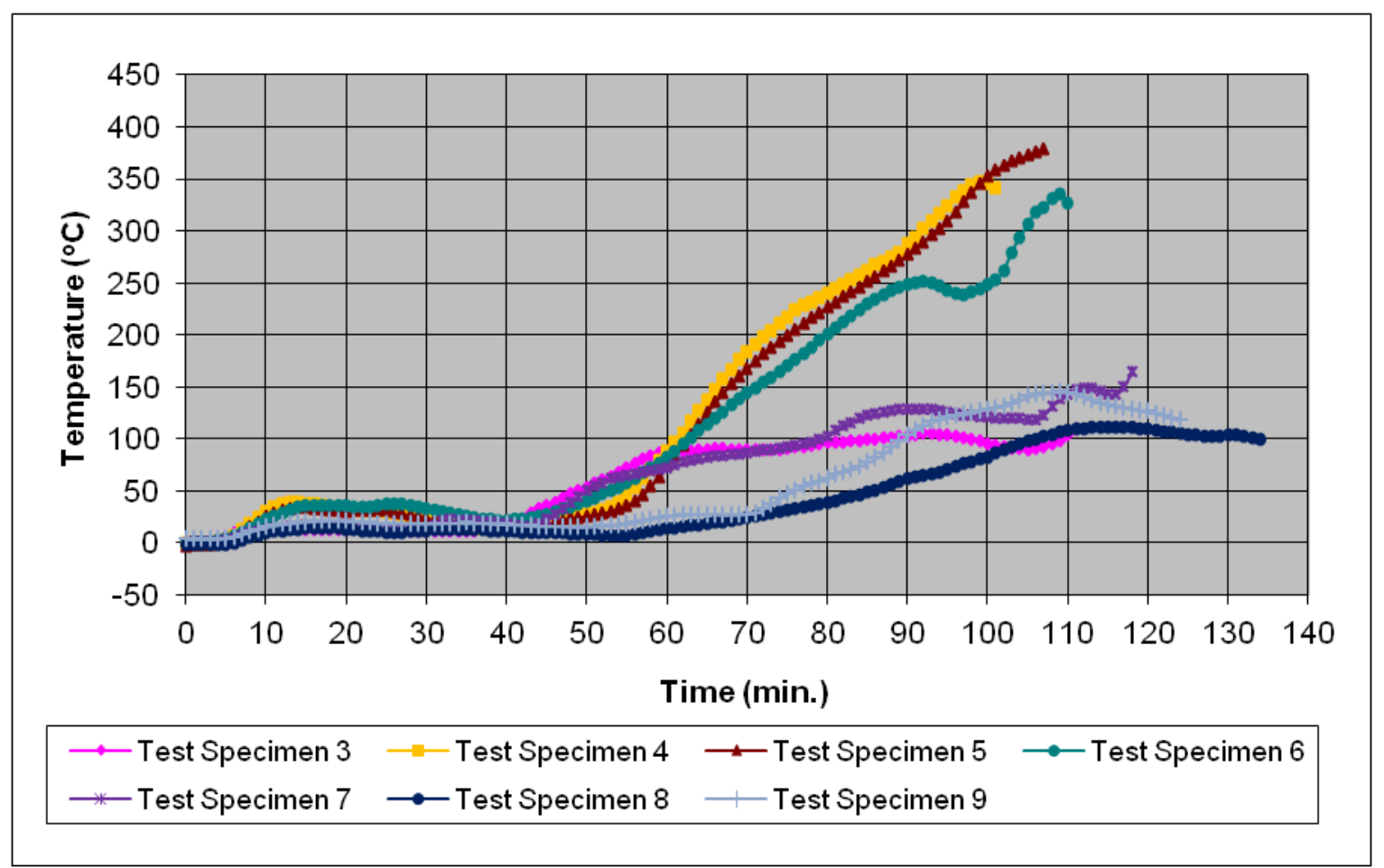

(b) Temperature Difference across the Studs

Figure 23: Average Temperature Profiles of the Critical Stud in Test Specimens 3 to 9 


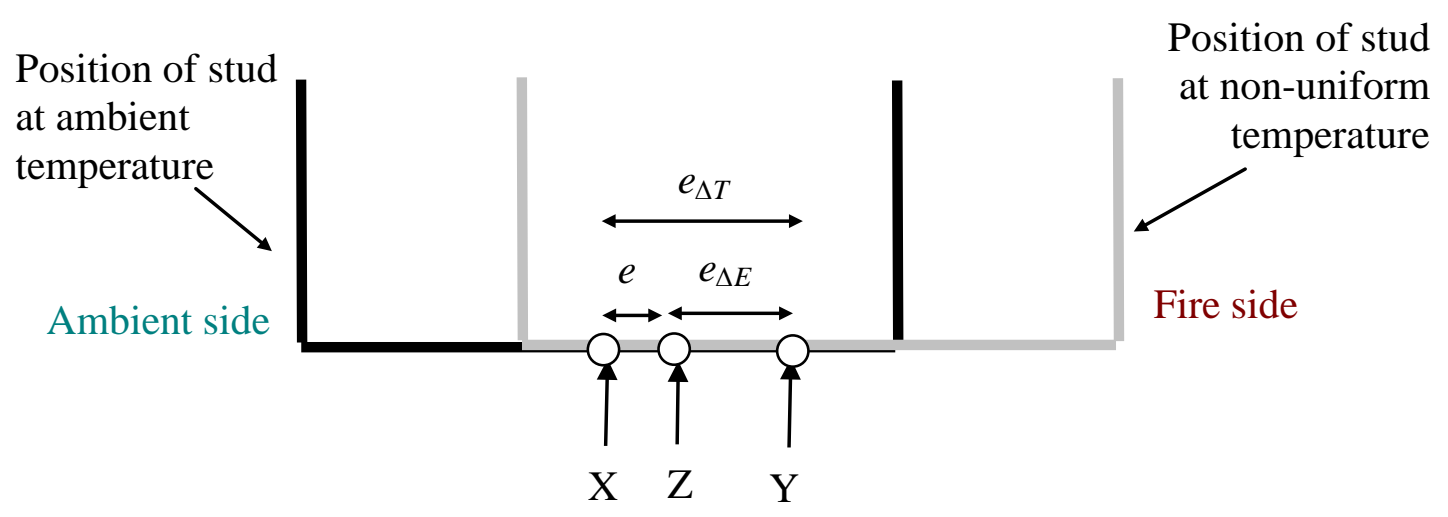

X: Position of centroid at the beginning of tests, and the point of Load application throughout the test.

Y: $\quad$ Position of centroid after taking into account thermal bowing.

Z: $\quad$ Position of centroid after taking into account thermal bowing and neutral axis shift.

$e_{\Delta T} \quad$ Eccentricity due to thermal bowing

$e_{\Delta E} \quad$ Eccentricity due to neutral axis shift

$e^{\quad \text { Net eccentricity }}$

Figure 24: Location of Effective Centroid of Studs in Relation to the Point of Load Application during Fire Tests 


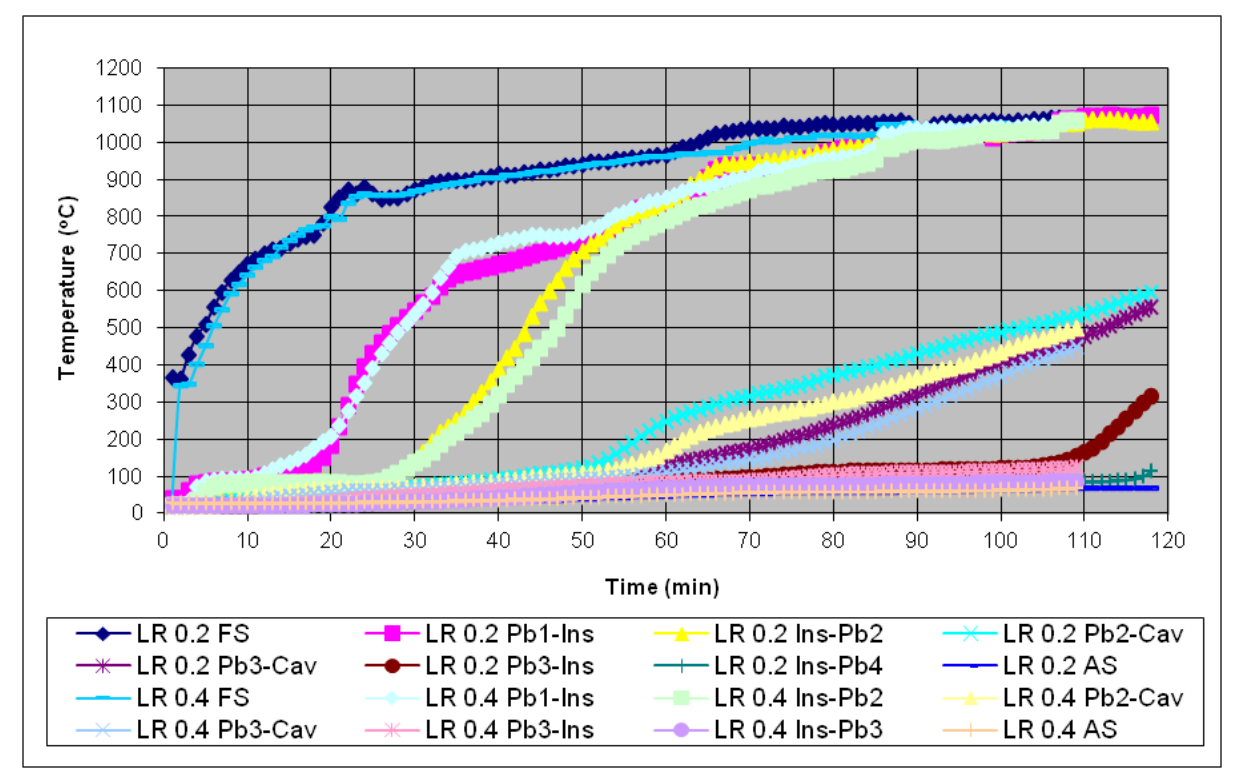

(a) Time - Temperature Profiles across the wall

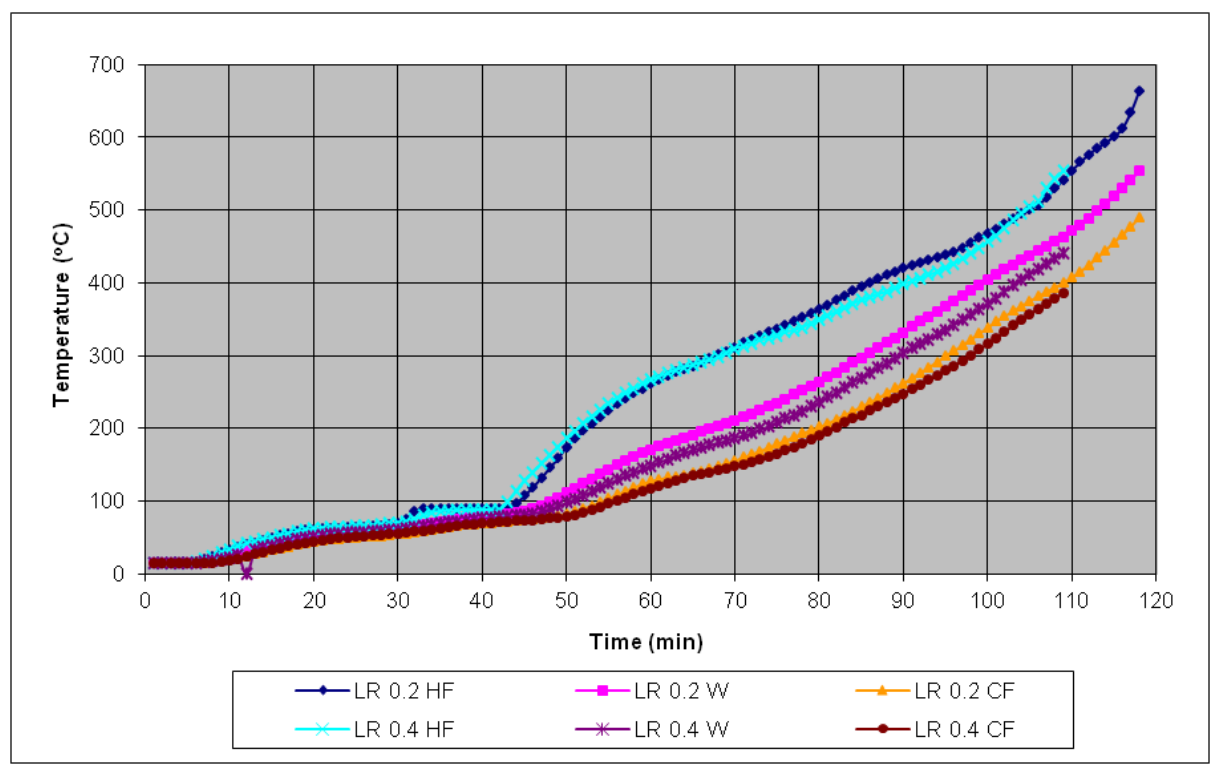

(b) Time - Temperature Profiles for the Critical Stud at Mid-height

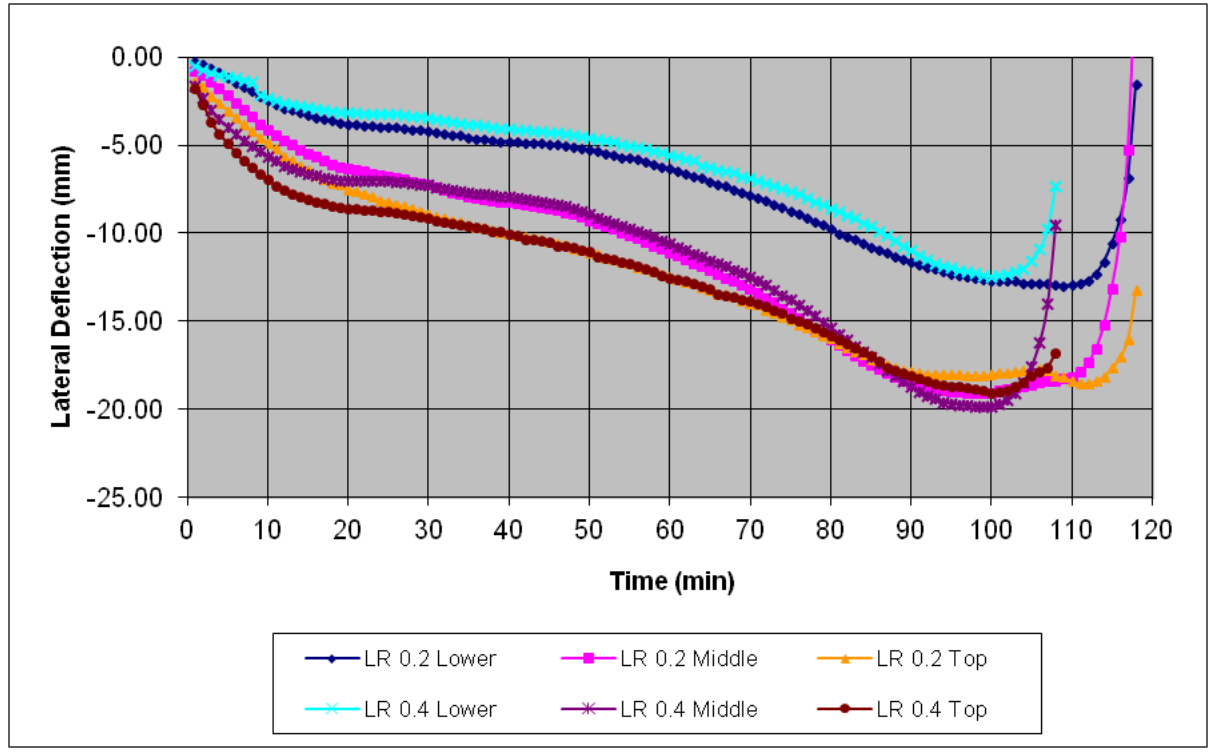

(c) Lateral Deflection - Time for the Critical Stud at Mid-height

Figure 25: Results for Test Specimens 7 and 10 